NBER WORKING PAPER SERIES

\title{
WHY IS LONG-HORIZON LESS RISKY? \\ A DURATION-BASED EXPLANATION OF THE VALUE PREMIUM
}

\author{
Martin Lettau \\ Jessica Wachter \\ Working Paper 11144 \\ http://www.nber.org/papers/w11144 \\ NATIONAL BUREAU OF ECONOMIC RESEARCH \\ 1050 Massachusetts Avenue \\ Cambridge, MA 02138 \\ February 2005
}

We thank Andy Abel, John Campbell, John Cochrane, Leonid Kogan, Sydney Ludvigson, Anthony Lynch, Stijn Van Niewerburgh, and seminar participants at the 2004 NBER Summer Institute, Duke University, New York University, the University of Pennsylvania, and Yale University for helpful comments. The views expressed herein are those of the author(s) and do not necessarily reflect the views of the National Bureau of Economic Research.

(C) 2005 by Martin Lettau and Jessica Wachter. All rights reserved. Short sections of text, not to exceed two paragraphs, may be quoted without explicit permission provided that full credit, including $\odot$ notice, is given to the source. 
Why is Long-Horizon Equity Less Risky? A Duration-Based Explanation of the Value Premium Martin Lettau and Jessica Wachter

NBER Working Paper No. 11144

February 2005

JEL No. G1

\begin{abstract}
This paper proposes a dynamic risk-based model that captures the high expected returns on value stocks relative to growth stocks, and the failure of the capital asset pricing model to explain these expected returns. To model the difference between value and growth stocks, we introduce a crosssection of long-lived firms distinguished by the timing of their cash flows. Firms with cash flows weighted more to the future have high price ratios, while firms with cash flows weighted more to the present have low price ratios. We model how investors perceive the risks of these cash flows by specifying a stochastic discount factor for the economy. The stochastic discount factor implies that shocks to aggregate dividends are priced, but that shocks to the time-varying price of risk are not. As long-horizon equity, growth stocks covary more with this time-varying price of risk than value stocks, which covary more with shocks to cash flows. When the model is calibrated to explain aggregate stock market behavior, we find that it can also account for the observed value premium, the high Sharpe ratios on value stocks relative to growth stocks, and the outperformance of value (and underperformance of growth) relative to the CAPM.
\end{abstract}

Martin Lettau

Department of Finance, Suite 9-190

Stern School of Business

New York University

44 West 4th Street

New York, NY 10012

and NBER

mlettau@stern.nyu.edu
Jessica Wachter

Department of Finance

2300 SH-DH

The Wharton School

University of Pennsylvania

3620 Locust Walk

Philadelphia, PA 19104

and NBER

jwachter@wharton.upenn.edu 


\section{Introduction}

This paper proposes a dynamic risk-based model that captures the high expected returns on value stocks relative to growth stocks, and the failure of the capital asset pricing model to explain these expected returns. The value premium, first noted by Graham and Dodd (1934), is the finding that assets with high ratios of price to fundamentals (growth stocks) have low expected returns relative to assets with low ratios of price to fundamentals (value stocks). This finding by itself is not necessarily surprising, as it is possible that the premium on value stocks represents a compensation for bearing systematic risk. However, Fama and French (1992) show that the capital asset pricing model (CAPM) of Sharpe (1964) and Lintner (1965) cannot account for the value premium. The CAPM predicts that expected returns should rise with the beta on the market portfolio; however, value stocks have higher expected returns yet do not appear to have higher betas than growth stocks.

To model the difference between value and growth stocks, we introduce a cross-section of long-lived firms distinguished by the timing of their cash flows. Firms with cash flows weighted more to the future have high price ratios, while firms with cash flows weighted more to the present have low price ratios. Drawing an analogy to bonds, we can say that growth firms are high-duration assets while value firms are low-duration assets.

We model how investors perceive the risks of these cash flows by specifying a stochastic discount factor for the economy, or equivalently, an intertemporal marginal rate of substitution for the representative agent. Our model for the stochastic discount factor shares some of the features of the external habit formation model of Campbell and Cochrane (1999). As in the model of Campbell and Cochrane (1999), the riskfree rate is constant. Moreover, we allow the price of risk to vary, implying that at certain times, investors require a greater return per unit of risk to hold equities than at others. A key difference is the relation between the price of risk and the aggregate dividend. In the model of Campbell and Cochrane (1999) they are tightly linked: a shock to the aggregate dividend moves agents closer to their habit level and raises the return they require for bearing risk. ${ }^{1}$ In our model the return investors require for bearing risk moves independently of the aggregate dividend. We show that the

\footnotetext{
${ }^{1}$ In the benchmark case of Campbell and Cochrane (1999), aggregate dividends and aggregate consumption are the same. Campbell and Cochrane also examine a case where dividends are correlated with consumption. Because of this correlation, there is still a link between dividends and the price of risk.
} 
correlation between the aggregate dividend and the price of risk determines, in large part, the ability of the model to fit the cross-section.

We require our model to explain not only the cross-section of assets based on price ratios, but also aggregate stock market behavior. Firms are distinguished by their cash flows which are defined in terms of shares of the aggregate dividend. We specify share processes that are stationary, and explore the robustness of our results to different models of the share process. This modeling strategy, also employed by Menzly, Santos, and Veronesi (2004) and Santos and Veronesi (2004), ensures that the economy is stationary, and that all future dividends are marketed. We assume that log dividend growth is normally distributed with a time-varying mean. We calibrate the dividend process to match conditional and unconditional moments of the aggregate dividend process in the data. Stochastic discount factor parameters are chosen to fit the time series of aggregate stock market returns. Expected excess returns on equity are time-varying in the model, implying excess volatility and return predictability. We find that the model can match unconditional moments of the aggregate stock market and produce predictability of dividends and returns close to that found in the data.

To test whether our model can capture the value premium, we sort firms into portfolios in simulated data. We find that risk premia, risk-adjusted returns, and Sharpe ratios increase as portfolios move from growth to value. The value premium (the return on a strategy that is long the extreme value portfolio and short the extreme growth portfolio) is between $3.4 \%$ and $5.2 \%$ (depending on the share process) compared with a value premium of $4.9 \%$ in the data when portfolios are formed on the basis of book-to-market. The CAPM alpha on the value-minus-growth strategy is between $4.7 \%$ and $6.2 \%$, compared with $5.6 \%$ in the data. These results do not arise because value stocks are more risky according to traditional measures; standard deviations and market betas increase slightly and then decrease, implying that the extreme value portfolio has a lower standard deviation and beta than the extreme growth portfolio. Our model therefore matches the magnitude of the value premium, and the outperformance of value portfolios relative to the CAPM, that is found in the data.

Our paper builds on previous literature that uses the concept of duration to better understand the cross-section of stock returns. Using the decomposition of returns into cash flow and discount rate components proposed by Campbell and Mei (1993), Cornell (1999) shows that growth companies, such as Amgen, whose cash flows are mainly idiosyncratic, may have high betas because of the duration of these cash flows, and the induced sensitivity 
of prices to market-wide changes in discount rates. Leibowitz and Kogelman (1993) show that accounting for the sensitivity of the value of long-run cash flows to discount rates can reconcile various measures of equity duration. Dechow, Sloan, and Soliman (2002) measure cash flow duration of value and growth portfolios; they find that empirically, growth stocks have higher duration than value stocks and that this contributes to their higher betas. Brennan and Xia (2003) show in a theoretical model that the beta on an asset increases in the maturity of the cash flows. Santos and Veronesi (2004) develop a model that links time variation in betas to time-variation in expected returns through the channel of duration, and show that this link is present in industry portfolios. Campbell and Vuolteenaho (2003) decompose the market return into news about cash flows and news about discount rates. They show that growth stocks have higher betas with respect to discount rate news than value stocks, consistent with the view that growth stocks are high duration assets. These papers all show that discount-rate risk is an important component of total volatility, and that growth stocks seem particularly subject to this discount-rate risk.

This paper also relates to the large and growing body of empirical literature that explores the correlations of returns on value and growth stocks with sources of systematic risk. This literature looks at either conditional versions of traditional models (Jagannathan and Wang (1996), Lettau and Ludvigson (2001), Zhang and Petkova (2002)), or identifies a new source of risk that covaries more with value stocks than with growth stocks (Lustig and VanNieuwerburgh (2002), Piazzesi, Schneider, and Tuzel (2002), Yogo (2003)). Another strand of literature relates observed returns on value and growth stocks to aggregate market returns or macro-economic factors (Brennan, Wang, and Xia (2003), Campbell, Polk, and Vuolteenaho (2003), Liew and Vassalou (2000), Parker and Julliard (2005), Vassalou (2003)). The results in these papers raise the question of what it is, fundamentally, about the cash flows of value and growth stocks that produces the observed patterns in returns. Other work examines the dividends on value and growth portfolios directly: Bansal, Dittmar, and Lundblad (2003) and Cohen, Polk, and Vuolteenaho (2002) find evidence that the cash flows of value stocks covary more with aggregate cash flows. The results in these papers raise the question of why this observed covariation leads to the value premium. Building on the work of Berk, Green, and Naik (1999), Gomes, Kogan, and Zhang (2003) and Zhang (2005) propose general equilibrium models that produce a cross-section of book-to-market ratios, where growth stocks have lower expected returns than value stocks. However, these 
models do not account for the classic finding of Fama and French (1992) that value stocks outperform and growth stocks underperform relative to the CAPM.

The paper is organized as follows. Section 2 organizes and updates the evidence that portfolios formed on the basis of prices scaled by fundamentals produce spreads in expected returns. We show that when value is defined by book-to-market, earnings-to-price, or cashflow-to-price, the expected return, Sharpe ratio, and alpha tend to increase as portfolios move from growth to value. The differences in expected returns and alphas between value and growth portfolios are statistically and economically large.

Section 3 presents our model for aggregate dividends and the stochastic discount factor. As a first step to solving for prices of the aggregate market and firms, we solve for prices of claims to the aggregate dividend $m$-periods in the future (zero-coupon equity). Because zero-coupon equity has a well-defined maturity, it provides a convenient window through which to view the role of duration in the model. Moreover, as the model has similarities to essentially affine term structure models (Dai and Singleton (2003), Duffee (2002)), the prices and risk premia on zero-coupon equity have interpretable, closed-form expressions. The aggregate market is the sum of all of the zero-coupon equity claims. We then introduce a cross-section of long-lived assets, defined by their shares in the aggregate dividend. These assets are themselves portfolios of zero-coupon equity, and together their cash flows and market values sum up to the cash flows and market values of the aggregate market.

Section 4 studies the implications of our model for the time series and the cross-section. We calibrate the model using the time series of the aggregate returns, dividends, and the price-dividend ratio. After choosing parameters to match aggregate time-series facts, we examine the implications for zero-coupon equity. We find that the parameters necessary to fit the time series imply risk premia, Sharpe ratios, and alphas for zero-coupon equity that are increasing in the maturity. Betas and volatilities are non-monotonic, and thus do not explain the increase in risk premia. This shows that the model has the potential to explain the value premium. We then choose parameters of the share process to approximate the distribution of dividend, earnings, and cash flow growth found in the data, and produce realistic distributions of price ratios. We examine several functional forms for the shares. When share processes are calibrated in this way, and the resulting assets are sorted into portfolios, our model can explain the observed value premium.

Section 5 describes the intuition for our results. We show that the covariation of asset 
returns with the shocks depends on the duration of the asset. Consistent with the results of Campbell and Vuolteenaho (2003), growth stocks have greater betas with respect to discount rates than value stocks. This is the duration effect: because cash flows on growth stocks are further in the future, their prices are more sensitive to changes in discount rates. Growth stocks also have greater betas with respect to changes in expected dividend growth. Value stocks, on the other hand, have greater betas with respect to shocks to near-term dividends. The price investors put on bearing the risk in each of these shocks determines the rates of return on value and growth stocks. While shocks to near-term dividends are viewed as risky by investors, shocks to expected future dividends are hedges under our calibration. Moreover, though discount rates vary over time, shocks to discount rates are independent of shocks to dividends and are therefore not priced directly. Even though long-horizon equity is riskier according to standard deviation and market beta, it is not seen as risky by investors because it loads on risks investors do not mind bearing.

\section{Evidence on the value premium}

Much previous literature has shown that portfolios of stocks with high ratios of prices to fundamentals have low future returns compared to stocks with low ratios of prices to fundamentals. $^{2}$ In this section, we update and organize this evidence by running statistical tests on portfolios formed on ratios of market to book value, price to earnings, price to dividends, and price to cash flow. We show that in all cases, the sorting produces differences in expected returns that cannot be attributed to market beta. Moreover, the alpha relative to the CAPM tends to increase in the measure of value. In our model, firms are distinguished on the basis of their cash flows, thus earnings, dividends, and cash flows are equivalent. For this reason, it is especially of interest to investigate whether the value effect is apparent in portfolios formed according to different measures of value.

Table 1 shows summary statistics for portfolios of firms sorted into deciles on the basis of the three characteristics described above, as well as on the basis of book-to-market. Data, available from the website of Ken French, are monthly, from 1952 to 2002. Excess returns

\footnotetext{
${ }^{2}$ See Graham and Dodd (1934), Basu (1977, 1983), Ball (1978), Rosenberg, Reid, and Lanstein (1985), Jaffe, Keim, and Westerfield (1989), and Fama and French (1992). Cochrane (1999) surveys recent literature on the value effect.
} 
are computed by subtracting monthly returns on the one-month Treasury Bill from the portfolio return. The first panel reports the mean excess return, the second the standard error on the mean, the third the standard deviation of the return, and the fourth the Sharpe ratio. Means and standard deviations are in annual percentage terms (multiplied by 1200 in the case of means and $\sqrt{12} \times 100$ in the case of standard deviations). Each panel reports results for the earnings-to-price ratio, the cash-flow-to-price ratio, the dividend yield, and the book-to-market ratio.

Panel 1 shows that for all measures except the dividend-yield, the mean excess return increases as one moves from the bottom scaled-price decile (growth stocks) to the top scaledprice decile (value stocks). The increase is usually, but not always, monotonic. As shown in Panel 2, the average return on the portfolio that is long the extreme value portfolio and short the extreme growth portfolio is highly statistically significant, again except when portfolios are formed on the basis of the dividend yield.

Panel 3 shows that the standard deviation of the excess return tends to decrease as one moves from the bottom decile to the top. This holds for all four scaled-price measures. Finally, Panel 4 shows that the Sharpe ratio increases as one moves from the bottom decile to the top across all four scaled-price measures. For example, when portfolios are formed on the basis of the earnings-to-price ratio, the bottom decile (growth) has a Sharpe ratio of 0.24. The Sharpe ratio increases steadily as the earnings-to-price ratio increases; the top decile has a Sharpe ratio of 0.72 . Value stocks not only deliver high returns; they deliver high returns per unit of standard deviation.

The results in Table 1 suggest that portfolios formed on the basis of earnings-to-price, cash-flow-to-price, dividend yield, and book-to-market, may be closely related. This is confirmed in Table 2, which shows the correlation of the bottom and top deciles. For the bottom decile (growth), the correlations are 0.93 or above; for the top decile (value), the correlations are 0.74 or above. In both cases, deciles formed by sorting on the dividend-yield are less highly correlated with the deciles formed by sorting on the other three variables than the deciles formed by sorting on the other three variables are with each other. This is consistent with the results in Table 1, which shows that results based on sorting on the dividend-yield were somewhat different than the other variables.

Following the same format as Table 1, Table 3 shows alphas, standard errors on alphas, betas, standard errors on betas, and $R^{2}$ statistics when portfolios are formed on the basis of 
each measure of value. The alpha is the intercept from an OLS regression of excess returns on the portfolio on excess returns on the value-weighted NYSE-AMEX-NASDAQ index, multiplied by 1200. Beta is the slope from this regression. The alpha for the portfolio that is long the extreme value portfolio and short the extreme growth portfolio is statistically significant for all four sorting variables. Panel 1 of this table confirms the classic result that value stocks have high alphas relative to the CAPM. The story is consistent across all sorting variables, including the dividend-yield: alphas are negative for growth stocks, rise as one moves from growth to value, and are positive for value stocks. As Panel 3 shows, betas tend to decline as one moves from growth to value, except for the extreme value portfolio. Thus value stocks have positive alphas relative to the CAPM, and relatively low betas.

This section shows that, in the data, value stocks have higher expected excess returns and higher Sharpe ratios than growth stocks. Value stocks have large positive alphas relative to the CAPM, while growth stocks have negative alphas. Moreover, value stocks do not have higher standard deviations or higher betas than growth stocks. Thus any story that explains the value premium needs to take into account the fact that value stocks do not appear to be riskier than growth stocks according to traditional measures of risk. These empirical results not only hold when value is defined by the book-to-market ratio, they hold when value is defined according to the earnings-to-price or cash-flow-to-price ratios.

\section{The model}

This section presents our model. The first subsection discusses the assumptions on aggregate cash flows and on the stochastic discount factor. The second subsection solves for prices on equity that pays the aggregate dividend in a fixed number of years from now; we refer to these claims as "zero-coupon equity" and they form the building blocks of our more complex assets. Interpretable, closed-form expressions are available for prices and conditional risk premia for zero-coupon equity. The third subsection describes how zero-coupon equity aggregates up to the market. The fourth subsection discusses the model for long-lived assets in terms of their shares in the aggregate dividend. These assets, like the aggregate market, are portfolios of zero-coupon equity and their prices can be determined accordingly. Thus the intuition for risk premia and price variation for zero-coupon equity can be transferred to these long-lived assets. 


\subsection{Dividend growth and the stochastic discount factor}

The model has three shocks: a shock to dividend growth, a shock to expected dividend growth, and a shock to the preference variable. To model these shocks in a parsimonious fashion, we let $\epsilon_{t+1}$ denote a $3 \times 1$ vector of independent normal shocks that have zero mean, unit standard deviation, and that are independent of any variables observed at time $t$. Let $D_{t}$ denote the aggregate dividend in the economy at time $t$, and $d_{t}=\ln D_{t}$. The aggregate dividend is assumed to follow the process

$$
\Delta d_{t+1}=g+z_{t}+\sigma_{d} \epsilon_{t+1}
$$

where $z_{t}$ follows the $\mathrm{AR}(1)$ process

$$
z_{t+1}=\phi_{z} z_{t}+\sigma_{z} \epsilon_{t+1}
$$

with $0 \leq \phi_{z}<1$. The conditional mean of dividend growth is $g+z_{t}$. Multiplying the shocks on dividend growth and $z_{t+1}$ are $1 \times 3$ vectors $\sigma_{d}$ and $\sigma_{z}$. The conditional standard deviation of $\Delta d_{t+1}$ equals $\left\|\sigma_{d}\right\|=\sqrt{\sigma_{d} \sigma_{d}^{\prime}}$. Similarly, the conditional standard deviation of $z_{t}$ equals $\left\|\sigma_{z}\right\|=\sqrt{\sigma_{z} \sigma_{z}^{\prime}}$, while the conditional covariance is given by $\sigma_{d} \sigma_{z}^{\prime}$. This model for dividend growth is also explored by Bansal and Yaron (2003), and by Campbell (1999).

We directly specify the stochastic discount factor for this economy. It is assumed that the price of risk is driven by a single state variable $x_{t}$ that follows the $\mathrm{AR}(1)$ process

$$
x_{t+1}=\left(1-\phi_{x}\right) \bar{x}+\phi_{x} x_{t}+\sigma_{x} \epsilon_{t+1},
$$

with $0 \leq \phi_{x}<1$. As above, $\sigma_{x}$ is a $1 \times 3$ vector. This specification for the price of risk is used in a continuous-time setting by Brennan, Wang, and Xia (2003). For simplicity, we assume that the real riskfree rate, denoted $r^{f}=\ln R^{f}$, is constant. Lastly, we need to make an assumption about which risks in the economy are priced. We could follow the affine term structure literature (see, e.g., Duffie and Kan (1996)) and allow all three shocks to be priced. For simplicity, and to reduce the number of degrees of freedom, we assume that only dividend risk is priced. This allows us to compare our models to the external habit formation models of Campbell and Cochrane (1999) and Menzly, Santos, and Veronesi (2004), where the one shock to the stochastic discount factor comes from aggregate consumption. The assumption that only dividend risk is priced implies that shocks to $z_{t}$ and shocks to $x_{t}$ will only be priced insofar as they correlate with $\Delta d_{t+1}$. 
This specification of $x_{t}, r^{f}$, and the fact that only dividend risk is priced completely pins down the stochastic discount factor. We set

$$
M_{t+1}=\exp \left\{-r^{f}-\frac{1}{2} x_{t}^{2}-x_{t} \epsilon_{d, t+1}\right\}
$$

where

$$
\epsilon_{d, t+1}=\frac{\sigma_{d}}{\left\|\sigma_{d}\right\|} \epsilon_{t+1}
$$

The conditional log-normality of $M_{t+1}$ implies that

$$
\begin{aligned}
\ln E_{t}\left[M_{t+1}\right] & =-r^{f}-\frac{1}{2} x_{t}^{2}+\frac{1}{2} x_{t}^{2} \sigma_{d} \sigma_{d}^{\prime}\left\|\sigma_{d}\right\|^{-2} \\
& =-r^{f}
\end{aligned}
$$

Therefore, it follows from no-arbitrage that $r^{f}$ is indeed the riskfree rate. The maximum Sharpe ratio will be achieved by the asset that is most negatively correlated with $M_{t+1}$. Following the same argument as in Campbell and Cochrane (1999), we note that the maximum Sharpe ratio is given by

$$
\frac{\sigma_{t}\left(M_{t+1}\right)}{E_{t}\left[M_{t+1}\right]}=\sqrt{e^{x_{t}^{2}}-1} \approx\left|x_{t}\right| .
$$

The question naturally arises of how to interpret the variable $x_{t}$. In the models of Campbell and Cochrane (1999) and Menzly, Santos, and Veronesi (2004), the price of risk is a decreasing function of the surplus consumption ratio. Conditionally, the price of risk is perfectly negatively correlated with consumption growth (and hence aggregate dividend growth). The corresponding assumption here would be to set $\sigma_{x} /\left\|\sigma_{x}\right\|=-\sigma_{d} /\left\|\sigma_{d}\right\|$. However, we depart from these papers by assuming that shocks to $x_{t+1}$ are uncorrelated with shocks to $\Delta d_{t+1}$ and shocks to $z_{t+1}$. In our model, shocks to $x_{t+1}$ can be interpreted as shocks to preferences or changes in sentiment. These shocks are uncorrelated with changes in fundamentals. Below, we explain the implications for security returns of this departure from habit formation.

\subsection{Prices of zero-coupon equity}

The building-blocks of the long-lived assets in our economy are "zero-coupon" equity. ${ }^{3}$ Let $P_{n t}$ be the price of an asset that pays the aggregate dividend $n$ periods from now. In this

\footnotetext{
${ }^{3}$ The notion of breaking the aggregate dividend into its zero-coupon claims, and using affine term structure techniques to calculate the value of these claims is also applied in Ang and Liu (2003), Bakshi and Chen (1996), Bekaert, Engstrom, and Grenadier (2004), Johnson (2002), Wachter (2003), and Wilson (2003).
} 
subsection, we solve for the price of zero-coupon equity in closed form. Let $R_{n, t+1}$ denote the one-period return on zero-coupon equity maturing in $n$ periods. That is,

$$
R_{n, t+1}=\frac{P_{n-1, t+1}}{P_{n t}}
$$

The returns $R_{n, t+1}$ form a term structure of equities, analogous to the term structure of interest rates. No-arbitrage implies the following Euler equation:

$$
E_{t}\left[M_{t+1} R_{n, t+1}\right]=1
$$

which implies that $P_{n t}$ and $P_{n-1, t}$ satisfy the recursive relation

$$
P_{n t}=E_{t}\left[M_{t+1} P_{n-1, t+1}\right]
$$

with boundary condition

$$
P_{0 t}=D_{t}
$$

because equity maturing today must be worth the aggregate dividend. We conjecture that a solution to (7) and (8) satisfies

$$
\frac{P_{n t}}{D_{t}}=F\left(x_{t}, z_{t}, n\right)=\exp \left\{A(n)+B_{x}(n) x_{t}+B_{z}(n) z_{t}\right\}
$$

By the boundary condition, it must be that $A(0)=B_{x}(0)=B_{z}(0)=0$. Substituting (9) into (7) produces

$$
E_{t}\left[M_{t+1} \frac{D_{t+1}}{D_{t}} F\left(x_{t+1}, z_{t+1}, n-1\right)\right]=F\left(x_{t}, z_{t}, n\right)
$$

Matching coefficients on $z_{t}, x_{t}$ and the constant implies that

$$
B_{z}(n)=\frac{1-\phi_{z}^{n}}{1-\phi_{z}}
$$

while $B_{x}(n)$ and $A(n)$ satisfy

$$
\begin{aligned}
B_{x}(n) & =B_{x}(n-1)\left(\phi_{x}-\sigma_{x} \frac{\sigma_{d}^{\prime}}{\left\|\sigma_{d}\right\|}\right)-\left(\sigma_{d}+B_{z}(n-1) \sigma_{z}\right) \frac{\sigma_{d}^{\prime}}{\left\|\sigma_{d}\right\|} \\
A(n) & =A(n-1)-r^{f}+g+B_{x}(n-1)\left(1-\phi_{x}\right) \bar{x}+\frac{1}{2} V_{n-1} V_{n-1}^{\prime}
\end{aligned}
$$

where

$$
V_{n-1}=\sigma_{d}+B_{z}(n-1) \sigma_{z}+B_{x}(n-1) \sigma_{x}
$$


and $B_{x}(0)=0, A(0)=0$. This confirms the conjecture $(9) .{ }^{4}$

Note that $B_{z}>0$ for all $n$. Intuitively, the higher is $z_{t}$, the higher is expected dividend growth, hence the higher is the price of equity that pays the aggregate dividend in the future. Because expected dividend growth is persistent, and because $D_{t+n}$ cumulates shocks between $t$ and $n$, the greater is $n$, the greater the effect of changes in $z_{t}$ on the price. Thus $B_{z}$ is increasing in $n$, and converges to $1 /\left(1-\phi_{z}\right)$ as $n$ approaches infinity.

The behavior of $B_{x}$ is more complicated. In our benchmark case of $\sigma_{x} \sigma_{d}^{\prime}=0, B_{x}(n)<0$ for all $n$. An increase in $x_{t}$ leads to an increase in risk premia and a decrease in prices. ${ }^{5}$ We further explore the intuition behind $B_{x}(n)$ in Section 4. Finally, $A_{n}$ is a constant term that determines the level of price-dividend ratios. The level depends on the average growth rate of dividends less the riskfree rate, as well as on the average level of the price of risk $(\bar{x})$. The remaining term, $\frac{1}{2} V_{n-1} V_{n-1}^{\prime}$ is a Jensen's inequality adjustment, and arises because we are taking the expectation of a log-normal variable.

In order to understand risk premia on the more complicated assets, it is helpful to understand risk premia on zero-coupon equity. Define $r_{n, t+1}=\ln R_{n, t+1}$. To gain an understanding of the model, we compute $\ln E_{t}\left[R_{n, t+1} / R^{f}\right]=E_{t}\left[r_{n, t+1}-r^{f}\right]+\frac{1}{2} \sigma_{t}\left(r_{n, t+1}\right) \sigma_{t}\left(r_{n, t+1}\right)^{\prime}$, following Campbell (1999). ${ }^{6}$ It follows from (9) that $r_{n, t+1}$ can be written as

$$
r_{n, t+1}=E_{t}\left[r_{n, t+1}\right]+\sigma_{t}\left(r_{n, t+1}\right) \epsilon_{t+1}
$$

where

$$
\sigma_{t}\left(r_{n, t+1}\right)=V_{n-1}=\sigma_{d}+B_{x}(n-1) \sigma_{x}+B_{z}(n-1) \sigma_{z}
$$

Therefore returns are conditionally log-normally distributed, and we can re-write the conditional Euler equation (6) as

$$
E_{t}\left[\exp \left\{-r^{f}-\frac{1}{2} x_{t}^{2}-x_{t} \epsilon_{d, t+1}+E_{t}\left[r_{n, t+1}\right]+\sigma_{t}\left(r_{n, t+1}\right) \epsilon_{t+1}\right\}\right]=1 .
$$

\footnotetext{
${ }^{4}$ The fact that price-dividend ratios are exponential affine in the state variables invites a comparison to the affine term structure literature, where bond prices are exponential affine in the state variables. In fact, this model is related to the essentially affine class of continuous-time term structure models explored by Dai and Singleton (2003) and Duffee (2002). Our model is essentially affine rather than affine because the stochastic discount factor is quadratic, as a result of the homoscedastic price-of-risk variable. Ang and Piazzesi (2003) examine a discrete-time essentially affine term structure model.

${ }^{5}$ In an alternative setting, it might be that $\left(\sigma_{d}+B_{z}(n-1) \sigma_{z}\right) \sigma_{d}<0$. In this case, an increase in $x_{t}$ would decrease risk premia and increase prices.

${ }^{6}$ When we match the simulated model to the data, we will compute $E\left[R_{t+1}-R^{f}\right]$.
} 
Taking logs of both sides and solving for the expectation produces the relation

$$
\begin{aligned}
E_{t}\left[r_{n, t+1}-r^{f}\right]+\frac{1}{2} \sigma_{t}\left(r_{n, t+1}\right) \sigma_{t}\left(r_{n, t+1}\right)^{\prime} & =\sigma_{t}\left(r_{n, t+1}\right) \frac{\sigma_{d}^{\prime}}{\left\|\sigma_{d}\right\|} x_{t} \\
& =\left(\sigma_{d}+B_{x}(n-1) \sigma_{x}+B_{z}(n-1) \sigma_{z}\right) \frac{\sigma_{d}^{\prime}}{\left\|\sigma_{d}\right\|} x_{t} .
\end{aligned}
$$

Risk premia on zero-coupon equity depend on the loadings on each of the sources of risk, multiplied by the "price" of each source of risk. In our base case, the term $\sigma_{x} \sigma_{d}^{\prime}$ disappears, so the loading on shocks to $x_{t}, B_{x}(n)$, is not relevant for risk premia on zero-coupon equity. In other cases we will examine, this term becomes important. Also determining risk premia is the loading on $z_{t}, B_{z}(n)$, and the price of $z_{t}$-risk, given by $\left\|\sigma_{d}\right\|^{-1} \sigma_{z} \sigma_{d}^{\prime} x_{t}$. In what follows, similar reasoning can be used to understand the price of risk of the aggregate market and of firms, all of which are portfolios of these underlying assets.

\subsection{Aggregate market}

The aggregate market is the claim to all future dividends. Accordingly, its price-dividend ratio is the sum of the ratios of price to aggregate dividends of the zero-coupon equity described in the section above. Thus

$$
\frac{P_{t}^{m}}{D_{t}}=\sum_{n=1}^{\infty} \frac{P_{n t}}{D_{t}}=\sum_{n=1}^{\infty} \exp \left\{A(n)+B_{x}(n) x_{t}+B_{z}(n) z_{t}\right\} .
$$

Appendix B gives necessary and sufficient conditions on the parameters such that (17) converges for all $x_{t}$ and $z_{t}$. The return on the aggregate market equals:

$$
\begin{aligned}
R_{t+1}^{m} & =\frac{P_{t+1}^{m}+D_{t+1}}{P_{t}^{m}} \\
& =\frac{\left(P_{t+1}^{m} / D_{t+1}\right)+1}{P_{t}^{m} / D_{t}} \frac{D_{t+1}}{D_{t}}
\end{aligned}
$$

\subsection{Firms}

Zero-coupon equity illustrates how duration matters for risk premia in a particularly stark way. However, there is no obvious analogue of zero-coupon equity in the data. Instead, in the data there are long-lived securities that pay a sequence of cash flows over time. We construct a cross-section of securities that sum up to the aggregate market portfolio. Moreover, we ensure that no one security comes to dominate the market portfolio over time; that is, the 
cross-sectional distribution of dividends, returns, and ratios of prices to aggregate dividends should be stationary. In order to accomplish this, we follow Lynch (2003) and Menzly, Santos, and Veronesi (2004) and specify the share each security has in the aggregate dividend process $D_{t+1}$. The continuous-time framework of Menzly, et al. allows them to specify the share process as stochastic, yet still keep shares between 0 and 1 . This is more difficult in discrete time, and for this reason we adopt the simplifying assumption that the share process is deterministic.

Suppose there are $N$ long-lived "firms" in the economy. Define an $N$-vector of shares, $s_{i}$, such that $s_{i} \geq 0$ and $\sum_{i=1}^{N} s_{i}=1$. At time $t$, we define firm $i$ as the asset that pays dividend $s_{i} D_{t}$ today, a dividend of $s_{i+1} D_{t+1}$ next period, etc. We specify $s_{i}$ as a function of $i$ for $1 \leq i \leq N$, and set

$$
\left.s_{i}=s_{(i-1} \bmod N\right)+1
$$

for $i>N$. By this definition, firm $i$ becomes firm $i+1$ next period. For example, at time $t$, firm 1 pays dividend $s_{1} D_{t}$ and has ex-dividend price:

$$
P_{1, t}^{F}=s_{2} P_{1, t}+s_{3} P_{2, t} \overbrace{+\cdots+}^{N-4 \text { terms }} s_{N} P_{N-1, t}+s_{1} P_{N, t}+s_{2} P_{N+1, t}+\cdots .
$$

At time $t+1$, this firm is now firm 2, pays dividend $s_{2} D_{t+1}$, and has ex-dividend price:

$$
P_{2, t+1}^{F}=s_{3} P_{1, t+1}+s_{4} P_{2, t+1} \overbrace{+\cdots+}^{N-5 \text { terms }} s_{N} P_{N-2, t+1}+s_{1} P_{N-1, t+1}+s_{2} P_{N, t+1}+s_{3} P_{N+1, t+1}+\cdots .
$$

Equation (6) implies that these prices are consistent with no-arbitrage:

$$
\begin{aligned}
E_{t}\left[M_{t+1}\left(s_{2} D_{t+1}+P_{2, t+1}^{F}\right)\right] & =s_{2} P_{1, t}+E_{t}\left[M_{t+1}\left(s_{3} P_{1, t+1}+\cdots+s_{N} P_{N-2, t+1}+s_{1} P_{N-1, t+1}+\cdots\right)\right] \\
& =s_{2} P_{1, t}+s_{3} P_{2, t}+\cdots+s_{N} P_{N-1, t}+s_{1} P_{N, t}+s_{2} P_{N+1, t}+\cdots \\
& =P_{1, t}^{F} .
\end{aligned}
$$

More generally, firm $k<N$ pays dividend $s_{k} D_{t}$ at time $t$ and has ex-dividends price

$$
P_{k, t}^{F}=s_{k+1} P_{1, t} \overbrace{+\cdots+}^{N-(k+2) \text { terms }} s_{N} P_{N-k, t}+s_{1} P_{N-k+1, t}+s_{2} P_{N-k+2, t}+\cdots,
$$

while firm $N$ pays dividend $s_{N} D_{t}$ and has price

$$
P_{N, t}^{F}=s_{1} P_{1, t}+s_{2} P_{2, t} \overbrace{+\cdots+}^{N-3 \text { terms }} s_{N} P_{N, t}+s_{1} P_{N+1, t}+s_{2} P_{N+2, t}+\cdots,
$$


and so forth. Note that firm $N$ becomes firm 1 next period. The same argument as above shows that these prices are consistent with no-arbitrage. This structure ensures that the economy is stationary, that in each period the sum of the dividends across all firms equals the aggregate dividend, and that all future dividends are marketed as of date $t$. Beyond these requirements, the key element of this structure is that it generates dispersion in when firms pay dividends. Other models of firms which generate such dispersion, such that the distribution of firms is stationary and sums to the market should yield results similar to those we describe below.

One implication of this modeling strategy is that ratios of prices to fundamentals forecast future growth opportunities in the cross-section. This is consistent with findings in the empirical literature. Bernstein and Tew (1991) show that firms with low dividend yields have higher forecasted growth rates, as measured by the mean five-year expected growth rate on IBES. Fama and French (1995) show that low book-to-market ratios correlate with higher future growth in earnings and profitability. Cohen, Polk, and Vuolteenaho (2003) show that low book-to-market firms have higher future return on equity than low book-tomarket firms, and that this predictive power extends fifteen years into the future.

Given the firm price $P_{k, t}^{F}$, the ratio of price to the one-period dividend equals

$$
\frac{P_{k, t}^{F}}{D_{k, t}^{F}}=\frac{P_{k, t}^{F}}{s_{k} D_{t}} .
$$

Because $P_{k, t}^{F} / D_{t}$ is a function of the state variables $x_{t}$ and $z_{t}$, the price-dividend ratio for the firm is also a function of the state variables. Returns on the firm are given by

$$
\begin{aligned}
R_{k, t+1}^{F} & =\frac{P_{k+1, t+1}^{F}+D_{k+1, t+1}^{F}}{P_{k, t}^{F}} \\
& =\frac{\left(P_{k+1, t+1}^{F} / D_{k+1, t+1}^{F}\right)+1}{P_{k, t}^{F} / D_{k, t}^{F}} \frac{D_{t+1}}{D_{t}} \frac{s_{k+1}}{s_{k}} .
\end{aligned}
$$

Note that all firms in this economy are ex-ante identical; they are simply "out of phase" with each other. Because of this, the market values of firms are very similar. A more complex model would be required to account for differences in firm size. 


\section{Implications for Equity Returns}

To study implications for the aggregate market and the cross-section, we simulate 50,000 quarters from the model. Given simulated data on shocks $\epsilon_{t+1}$ and state variables $x_{t+1}$ and $z_{t+1}$, we compute ratios of prices to aggregate dividends for zero-coupon equity from (9), the price-dividend ratio for the aggregate market from (17), and the price-dividend ratio for firms from (19). Returns can then be computed using (5) for zero-coupon equity, (18) for the market, and (20) for firms.

As discussed below, we calibrate the model to the annual data set of Campbell (1999) that begins in 1890. We update Campbell's data (which ends in 1995) until the end of 2002. So that our simulated values are comparable to the annual values in the data, we aggregate up to an annual frequency. Annual flow variables (returns, dividend growth) are constructed by compounding their quarterly counterparts. Price-dividend ratios for the market and for firms are constructed analogously to annual price-dividend ratios in the Campbell data set. We divide the price by the current dividend on the asset, plus the previous three quarters of dividends on the asset.

Section 4.1 describes the calibration of our model to the aggregate time series. Section 4.2 shows the implications for the behavior of the aggregate market and dividend growth and discusses the fit to the data. Section 4.3 discusses implications for prices and returns on zero-coupon equity. While zero-coupon equity have no analogue in the data, they are a useful construct in that they allow us to illustrate the properties of the model in a stark way. Section 4.4 discusses the calibration of the share processes which determine the prices of long-lived assets ("firms"), and describes implications of the model for portfolios formed on the basis of scaled-price ratios.

\subsection{Calibration}

Following Menzly, Santos, and Veronesi (2004), we calibrate the model to provide a reasonable fit to aggregate data. We then ask whether the model can match moments of the cross-section. In order to accurately capture the characteristics of our persistent processes, we use the century-long annual data set of Campbell (1999), which we update through 2002. The riskfree rate is the return on 6-month commercial paper purchased in January and rolled over in July. Stock returns, prices, and dividends are for the S\&P 500 index. More details 
on data construction are contained in the Data Appendix of Campbell (1999). All variables are adjusted for inflation.

We set $r^{f}$ equal to $1.93 \%$, the mean of the riskfree rate in our sample. The average dividend growth in the sample is $2.28 \%$, therefore this is our value for $g$. It is less straightforward to calibrate the process $z_{t}$, which determines expected dividend growth. This process, strictly speaking, is unobservable to the econometrician. However, Lettau and Ludvigson (2002) show that if consumption growth follows a random walk and if the consumptiondividend ratio is stationary, the consumption-dividend ratio captures all the predictability in dividend growth. Therefore the consumption-dividend ratio can be identified with $z_{t}$ up to an additive and multiplicative constant.

For the purposes of calibration, we adopt the set-up of Lettau and Ludvigson (2002) and calibrate the autocorrelation of $z_{t}$ and the correlation between shocks to expected dividend growth and shocks to $z_{t}$ using the consumption-dividend ratio. ${ }^{7}$ In our annual sample, the consumption-dividend ratio has a persistence of 0.91 and a conditional correlation with dividend growth of -0.83. This still leaves the conditional standard deviations $\left\|\sigma_{d}\right\|$ and $\left\|\sigma_{z}\right\|$. We set $\left\|\sigma_{d}\right\|$ to match the unconditional standard deviation of annual dividend growth in the data. ${ }^{8}$ Our empirical results imply a standard deviation of $z_{t}$ that is small relative to the standard deviation of dividend growth. Despite the fact that dividend growth is predictable at long horizons by the consumption-dividend ratio, the consumption-dividend ratio has very little predictive power for dividend growth at short horizons (with an $R^{2}$ of $3 \%$ ). Moreover, the autocorrelation of dividend growth is relatively low (-.09\%). We show that $\left\|\sigma_{z}\right\|=.0016$ (.0032 per annum) produces similar results in simulated data.

Remaining parameters are $\bar{x}, \phi_{x}$, and $\left\|\sigma_{x}\right\|$. Because the variance of expected dividend growth is small, the autocorrelation of the price-dividend ratio is primarily determined by the autocorrelation of $x$. We therefore set $\phi_{x}=0.87^{\frac{1}{4}}=0.966$, as 0.87 is the autocorrelation of the price-dividend ratio in annual data. We choose $\left\|\sigma_{x}\right\|$ to equal 0.12 , or 0.24 per annum, to match the volatility of the log price dividend ratio. We choose $\bar{x}$ so that the maximal

\footnotetext{
${ }^{7}$ An equivalent way of writing down our model would be to assume a process, called consumption, that follows a random walk, and model the consumption-dividend ratio as an AR(1) process. Note however that consumption plays no special role in our model.

${ }^{8}$ The model is simulated at a quarterly frequency and aggregated up to an annual frequency. Because dividend growth is slightly mean reverting, and because the variance of $z_{t}$ is small, this results in an unconditional annual standard deviation of dividend growth very close to that in the data.
} 
Sharpe ratio, when $x_{t}$ is at its long-run mean, is 0.70 . This produces Sharpe ratios for the cross-section that are close to those in the data. Setting the maximum Sharpe ratio $\sqrt{e^{\bar{x}^{2}}-1}$ equal to 0.70 translates into $\bar{x}=0.625$. As discussed in the subsequent section, this produces an average Sharpe ratio for the market that is 0.41 , somewhat higher than the data equivalent of 0.33 . However, expected stock returns are measured with noise, and 0.41 is still below the Sharpe ratio in postwar data.

To link the conditional standard deviation of $\Delta d_{t+1}, z_{t+1}$, and, $x_{t+1}$, and the conditional correlation of $\Delta d_{t+1}$ and $z_{t+1}$ with the vectors $\sigma_{d}, \sigma_{z}, \sigma_{x}$, we assume, without loss of generality, that the $3 \times 3$ matrix

$$
\left[\begin{array}{c}
\sigma_{d} \\
\sigma_{z} \\
\sigma_{x}
\end{array}\right]
$$

is lower triangular. Thus

$$
\epsilon_{1, t+1}=\epsilon_{d, t+1}
$$

so that $\sigma_{d}$ has a nonzero first element equal to $\left\|\sigma_{d}\right\|$ and zero second and third elements. $\sigma_{z}$ has a nonzero first and second element and zero third element. The first two elements are identified by $\left\|\sigma_{z}\right\|$ and the covariance $\sigma_{d} \sigma_{z}^{\prime}$. We focus on the case where $x_{t+1}$ is independent of $\Delta d_{t+1}$ and $z_{t+1}$, so the first and second elements of $\sigma_{x}$ equal zero, and the third equals $\left\|\sigma_{x}\right\|$. Table 4 summarizes these parameter choices.

\subsection{Implications for the Aggregate Market and Dividend Growth}

Table 5 presents statistics from simulated data, and the corresponding statistics computed from actual data. The volatility of the price-dividend ratio is fit exactly, and the autocorrelation of the price-dividend ratio is very close ( 0.87 in the data versus 0.88 in the model). This is not a surprise because $\left\|\sigma_{x}\right\|$ and $\phi_{x}$ were set so that the model fits these parameters. The model produces a mean of the price-dividend ratio equal to 20.1, compared to 25.6 in the data. Matching this statistic is a common difficulty for models of this type: for example, Campbell and Cochrane (1999) find an average price-dividend ratio of 18.2. As they explain, this statistic is poorly measured due to the persistence of the price-dividend ratio. The model fits the volatility of equity returns $(19.2 \%$ in the model versus $19.4 \%$ in the data), though it produces an equity premium that is slightly higher than in the data $(7.9 \%$ in the model 
versus $6.3 \%$ in the data). As with the mean of the price-dividend ratio, the average equity premium is measured with noise. In the long-annual data set, the annual auto-correlation of returns is slightly positive (.03). In our model, the auto-correlation is slightly negative (-.02). The autocorrelation of dividend growth is small and negative (-.03), just as in the data (-.09).

Table 6 reports the results of long-horizon regressions of continuously compounded excess returns on the log price-dividend ratio in the model and in the data. In our sample, as elsewhere (see Campbell and Shiller (1988), Cochrane (1992), Fama and French (1989), and Keim and Stambaugh (1986)), high price-dividend ratios predict low returns. The coefficients rise with the horizon. The $R^{2}$ s start small, at 0.05 at an annual horizon, and rise to 0.31 at a horizon of ten years. The t-statistics, using auto-correlation and heteroscedasticityadjusted standard errors, are significant at the $5 \%$ level. The simulated data exhibits the same pattern. The coefficients rise with the horizon. The $R^{2}$ s start at 0.06 and rise to 0.28. We conclude that the model generates a reasonable amount of return predictability. ${ }^{9}$

Table 6 reports the results of long-horizon regressions of dividend growth on the pricedividend ratio. As Campbell and Shiller (1988) show, dividend growth is not predictable by returns, contrary to what might be expected from a dividend-discount model. This result also holds true in our data set: the coefficients from a regression of dividend growth on the price-dividend ratio are always insignificant and are accompanied by small $R^{2}$ statistics. In contrast, the consumption-dividend ratio predicts dividend growth. The coefficients are significant, and the adjusted $R^{2}$ statistics start at $3 \%$ for an annual horizon and rise to $25 \%$ for a horizon of ten years.

Our model replicates both of these findings. Despite the fact that the mean of dividends is time-varying, dividends are only slightly predictable by the price-dividend ratio. A regression of simulated dividend growth on the simulated price-dividend ratio produces $R^{2}$ s that range from $2 \%$ to $9 \%$ at a horizon of 10 years (in the data, the adjusted $R^{2}$ s range from 0 to $5 \%$ ). By contrast, dividends are predictable by $z_{t}$. Here, the $R^{2}$ s range from $4 \%$ to $24 \%$, close to the values in the data. We conclude our model captures the pattern of dividend

\footnotetext{
${ }^{9}$ Lettau and Ludvigson (2002) find evidence that excess returns are predictable by expected dividend growth, as well as by the price-dividend ratio. This effect can be captured in our model by allowing shocks to $x_{t}$ to be positively correlated with shocks to $z_{t}$. Introducing this positive correlation has very little effect on our cross-sectional results, hence for simplicity we focus on the case of zero correlation.
} 
predictability found in the data.

\subsection{Prices and Returns on Zero-Coupon Equity}

Figure 1 plots the solution for $A(n), B_{z}(n)$ and $B_{x}(n)$ as a function of $n$ for the parameter values given above. $A(n)$ is steadily decreasing. This is a necessary feature for convergence of the solution for all $x_{t}$ and $z_{t}$, and it makes economic sense: the further the payoff is in the future, the lower the value of the security when the state variables are at their long-run means. What generates the decrease is the positive average price of risk $\bar{x}$ and riskfree rate $r^{f}$. Counteracting this decrease is average dividend growth $g$ and the Jensen's inequality term. The net effect is that $A(n)$ is decreasing in $n$.

In contrast, $B_{z}(n)$ is positive, is increasing in maturity $n$, and asymptotes to a value of $1 /\left(1-\phi_{z}\right)$. The intuition for this variable is explained in Section 3.1. As discussed in Section $3.1, B_{x}(n)$ is negative. This implies that an increase in the price of risk $x_{t}$ leads to a decrease in valuations. Note that $B_{x}(n)$ is non-monotonic in $n$. It starts at 0 , decreases to below -1 , then increases, and eventually converges to a value near -0.5. It is not surprising that $B_{x}(n)$ initially decreases in maturity. This is the duration effect: the longer the maturity, the more sensitive is the price to changes in the discount rate. More curious is the fact that $B_{x}$ rises after a maturity of 50 quarters. This is because the duration effect is countered by the increase in $B_{z}(n)$. Because expected dividend growth and dividend growth are negatively correlated, shocks to expected dividend growth act as a hedge. Moreover, as the plot of $B_{z}$ shows, expected dividend growth becomes more important the longer the maturity of the equity. Therefore equity that pays in the far future is less sensitive to changes in $x_{t}$ than equity that pays in the medium term, though both are more sensitive than short-horizon equity.

Figure 2 plots the ratios of price to aggregate dividends for zero-coupon equity as a function of maturity. The top panel sets $z_{t}$ to be two long-run standard deviations $\left(2\left\|\sigma_{z}\right\| /(1-\right.$ $\left.\phi_{z}^{2}\right)^{1 / 2}$ ) below its long-run mean, the middle panel to the long-run mean of zero, and the bottom panel to two long-run standard deviations above the long-run mean. Each panel plots the price-dividend ratio for $x_{t}$ at its long run mean and two long-run standard deviations $\left(2\left\|\sigma_{x}\right\| /\left(1-\phi_{x}^{2}\right)^{1 / 2}\right)$ above and below the long-run mean. Not surprisingly, prices are increasing in expected dividend growth $z_{t}$ for all values of $x_{t}$ and for all values of the maturity. Moreover, 
for all values of the maturity and all values of $z_{t}$, prices decrease in $x_{t}$. The higher are conditional expected returns, the lower are prices.

For most values of $z_{t}$ and $x_{t}$, prices decline with maturity. Generally, the further in the future the asset pays the aggregate dividend, the less it is worth today. Exceptions occur when $x_{t}$ is two standard deviations below its long-run mean. In this cases, the premium for holding risky securities is negative in the short term, so short-horizon payoffs are discounted by more than long-horizon payoffs. Because $x_{t}$ reverts back to its long-run mean, this effect is transitory and only holds at the short end of the equity "yield curve". The greater is $z_{t}$, the longer the effect persists, as when expected dividend growth is high, equity that pays the aggregate dividend further in the future will go up in price more than equity that pays the aggregate dividend in the present. When $z_{t}$ is two standard deviations above its long-run mean and $x_{t}$ is two standard deviations below its long-run mean, the price of zero-coupon equity increases with maturity out to about 7 years, and then decreases again.

Figure 3 shows statistics for annual returns on zero-coupon equity. Annual returns are calculated by compounding quarterly returns defined by (5). The top panel shows that the risk premium $E R_{i, t+1}-R^{f}$ decreases monotonically with maturity. The effect is economically large: for equity that pays a dividend in the next two years, the risk premium is $18 \%$ while the risk premium declines to $4 \%$ for equity that pays a dividend 40 years from now.

The second panel of Figure 3 plots the volatility of annual returns. The volatility initially increases with maturity, and then begins to decrease monotonically at a maturity of ten years. For long-horizon equity, increased risk premia are not accompanied by increased standard deviations. The third panel of Figure 3 shows that the unconditional Sharpe ratio declines monotonically in maturity from a value of 0.8 to a value of 0.2 . Even for short-horizon equity, the volatility increases less than the mean. These results suggest that the model has the potential to explain the patterns described in Table 1. Those firms that have more weight in lower-maturity equity will have higher expected returns, higher Sharpe ratios, and possibly lower variance, than firms that have more weight in equity of greater maturity.

Figure 4 shows the results of regressing simulated returns on zero-coupon equity on simulated returns on the market portfolio. The top panel plots the regression alpha, the middle panel the beta, and the last panel the $R^{2}$ from the regression. As in Figure 3, returns are annual. The first panel shows that the alpha relative to the CAPM is decreasing in maturity over most of the range, and increases very slightly for long-duration equity. For the 
shortest-duration equity the alpha is as high as $11 \%$. The alpha falls below zero for equity maturing in 5 or more years, but remains above $-5 \%$. Thus the model produces relatively large positive alphas and relatively small negative alphas, just as in the data, as shown in Table 3 .

The second panel of Figure 4 shows the beta. The beta first increases, and then, beginning with a maturity of about ten years, decreases slowly as a function of maturity. The betas for zero-coupon equity lie in a relatively narrow range; the lowest beta (for very long horizon equity) is about 0.7. The highest beta (for equity of about ten years ) is 1.5. The beta for the shortest-horizon equity is about 0.9. This plot shows that at least for short-horizon equity, high alphas are not necessarily accompanied by high betas. This also gives the model the potential to match the data described in Table 3.

While the simplicity of zero-coupon equity makes it a convenient way to illustrate the properties of the model, it does not have a direct interpretation in terms of value and growth. The price-dividend ratio is not well-defined because zero-coupon equity only pays dividends during a single quarter. For this reason, we turn to a model of firms: long-lived assets that have nonzero cash flows in every period.

\subsection{Implications for the Cross-Section of Returns}

This section shows the implications of the model for portfolios formed on the basis of price ratios. Following Menzly, Santos, and Veronesi (2004), we exogenously specify a share process for cash flows on long-lived assets. In each year of simulated data, we sort these assets into deciles based on the ratio of price to dividends (or equivalently, earnings or cash flows) and form portfolios of the assets within each decile. This follows the procedure used in empirical studies of the cross-section (e.g. Fama and French (1992)). We then perform statistical analysis on the portfolio returns.

\section{Specifying the share process}

As described in Section 3.4, specifying a model for firms is equivalent to specifying a sequence

$s_{1}, \ldots, s_{N}$ of dividend shares, such that $\sum_{i=1}^{N} s_{i}=1$. As explained in Section 3.4, firm $i$ pays dividend $s_{i} D_{i, t}$ at time $t, s_{i+1} D_{i, t+1}$ at time $t+1$, etc. At time $t+1$, firm $i$ becomes firm $i+1$. We choose two functional forms for $s_{i}$ to illustrate the implications of our model 
for a cross-section of long-lived assets. While this model for firms is simple and somewhat mechanical, it accomplishes our objective of creating dispersion in the timing of cash flows across firms in a straightforward way.

The first functional form assumes that the rate of growth in the shares falls linearly in $i$ :

$$
\frac{s_{i+1}}{s_{i}}=g_{0}\left(1-\frac{i-1}{N / 2-1}\right)
$$

for $i=1, \ldots, N-1$. The value of $s_{1}$ is set so the weights sum to 1 . For the first $N / 2$ quarters, the firm's share in the aggregate dividend process grows, each year at a slower rate. After 100 quarters, the share in the aggregate dividend process declines. Eventually, the firm's share in the aggregate dividend process becomes negligible. At this point the share begins to grow again, as described in Section 3.4. A possible interpretation is that the capital invested in the dying firm is used to fund a new, growing firm.

As a robustness check, we examine a second functional form. The second functional form assumes that the rate of growth in the shares is a positive constant $g_{1}$ for the first half of the firm's life-cycle, and $-g_{1}$ for the second half of the firm's life-cycle. In other words,

$$
\frac{s_{i+1}}{s_{i}}=g_{1}
$$

for $i=1, \ldots, N / 2-1 ; 0$ for $i=N / 2$; and

$$
\frac{s_{i+1}}{s_{i}}=-g_{1}
$$

for $i=N / 2+1, \ldots, N-1$. Once again, the value of $s_{1}$ is set so that the weights sum to 1. We calibrate each specification for firm shares using data on the cross-section of cash flows and price-dividend ratios. Here and throughout, we set the number of firms to be 200, implying a 200-quarter, or equivalently, a 50-year life cycle for a firm.

We first describe the calibration for the model with linearly declining growth. The parameter that controls the shrinking growth rate, $g_{0}$, is set so that the cross-section of dividend growth rates matches the cross-section of firms in the sample. Because data on earnings and cash flows are not available prior to 1952, we construct the cross-section for data from 1952 to $2002 .{ }^{10}$ The parameter $g_{0}$ is set to be $0.75 / 4$, for a per-annum value

\footnotetext{
${ }^{10}$ Adrian and Franzoni (2002) Ang and Chen (2003), and Campbell and Vuolteenaho (2003) show that value stocks have higher betas in the pre-war period, so the CAPM performs better. By matching the crosssection to the postwar data, we choose a harder target. We also assume that agents observe the parameters in the economy. Lewellen and Shanken (2002) show that introducing learning into a traditional model can help in understanding value premia.
} 
of 0.75. The specification (21) then implies that firms start their life cycle with an annual growth rate of $75 \%$, growth declines to $0 \%$ after 25 yeas, and reaches $-75 \%$ after another 25 years to complete one cycle. The top panel of Figure 5 plots the implied expected growth rate of dividends for firms in the model, as well as the cross-section of average growth rates in earnings, dividends, and cash flows. Because the firms in our model have no debt, the dividends in our model may be better analogues to earnings and cash flows in the data, rather than dividends themselves. As the top panel of Figure 5 shows, the linear model with $g_{0}$ set at $0.75 / 4$ does a reasonable job of fitting the cross-section of growth rates in the data.

The second panel of Figure 5 shows the distribution of firm price-dividend ratios in the model, and price ratios in the data. The linearly declining growth model for shares produces more high price-dividend ratio firms than there are in the data. These firms have high price-dividend ratios because they have extremely low current dividends. It is possible to construct a model that fits the distribution more closely by imposing a lower bound on the dividend share, at the cost of a somewhat more complicated functional form for $s_{i}$. This modification is pursued in Appendix A.

Figure 6 shows corresponding results for the model with constant growth in shares. When calibrated with an annual growth rate of $20 \%\left(g_{1}=.20 / 4=.05\right)$, the model with constant growth produces a reasonable fit to the cross-section of dividend, earnings, and cash-flow growth in the data, despite its simplicity. A drawback of the constant growth model is the frequency of very high or very low dividend growth rates. This aspect of the distribution is better matched with the linear-growth model. However, the constant-growth model produces a superior fit to the cross-section of price ratios, as shown in the second panel of Figure 6.

We conclude that the linearly declining growth and the constant growth model produce reasonable cross-sections of dividend growth and price-dividend ratios. As we will show, our results for portfolio statistics are very similar, regardless of which model we use. This suggests that our results will be robust to a range of cross-sectional distributions for firm dividend growth.

\section{Portfolio returns}

At the start of each year in the simulation, we sort firms according to their price-dividend ratio into deciles. We then form equal-weighted portfolios of the firms in each decile. As 
firms move through their life-cycle, they slowly shift (on average) from the growth category to the value category, and then revert back eventually to the growth category. Of course, this process is not deterministic, just as it is not deterministic in the data. Shocks have different impacts on the price-dividend ratio, the variable that determines the appropriate decile for the firm.

Having sorted the firms into deciles at the beginning of each "year", we compute statistical tests on returns over the year. Table 8 shows results for the linearly declining share growth specification; Table 9 shows results for constant share growth specification. Because the results are quantitatively similar, we discuss only Table 8.

The first panel of Table 8 shows the expected excess return, the standard deviation, and the Sharpe ratio for each portfolio. These simulation results should be compared to the numbers in Table 1, which shows corresponding results for the data. The expected return on extreme growth stocks is $4.44 \%$ per annum, while for extreme value stocks, it is $9.65 \%$ per annum. ${ }^{11}$ A similar spread occurs in the data: the lowest book-to-market stocks have a premium of $5.67 \%$, while the highest have a premium of $10.55 \%$. The model generates reasonable volatilities; between $19 \%$ and $17 \%$. The volatilities for book-to-market sorted portfolios vary between $18 \%$ and $15 \%$ in the data. The model predicts that the volatility decreases as one moves from the growth to the value portfolio, so growth stocks are actually more volatile than value stocks, despite the lower return. This effect is also found in the data. The model predicts that the Sharpe ratio for the extreme growth stocks is 0.23 , and for the extreme value stocks is 0.57 , and that the Sharpe ratio increases in the decile number. In the data, the low book-to-market portfolio has a Sharpe ratio of 0.32 while the high bookto-market portfolio has a Sharpe ratio of 0.57. To summarize, in the model, value stocks have high expected returns, low volatility, and high Sharpe ratios, just as in the data. The magnitude of the difference between value and growth is comparable to that in the data.

The second panel of Table 8 shows alphas and betas relative to the CAPM. Annual excess portfolio returns are regressed on excess returns on the aggregate market (the claim

\footnotetext{
${ }^{11}$ Here and throughout this section, we compare the statistics on annual returns in the model to statistics on monthly returns in the data. The monthly data statistics are annualized as described in Section 2 . We choose this approach because it corresponds most closely to the approach taken in the empirical literature on the value premium. Data results for annual returns are very similar to those in Tables 1-3 (except for standard errors).
} 
to all future dividends). Alpha, beta and the $R^{2}$ are reported for each decile. The second panel shows that the model can replicate the classic result of Fama and French (1992): value portfolios have positive alphas relative to the CAPM, while growth portfolios have negative alphas. Moreover, value portfolios tend to have lower betas than growth portfolios. Our model predicts alphas that rise from -2.86 for the extreme growth portfolio, to 3.30 for the extreme value portfolio. In the data, the lowest book-to-market portfolio has an alpha of -1.66, while the highest book-to-market portfolio has an alpha of 3.97. Thus the model generates alphas of the correct magnitude, as well as a sizable spread between value and growth. Moreover, alphas in the model are asymmetric: growth alphas are smaller in absolute value than value alphas, as in the data.

The third panel of Table 8 runs regressions of portfolio returns on the market and on a high-minus-low factor (HML), generated by the return on a short position in the extreme growth portfolio and a long position in the extreme value portfolio. The purpose is to see whether the model analogue to the high-minus-low factor of Fama and French (1992) describes the cross-section of returns in the model, as it does in the data. We find that the alphas nearly disappear when we add HML to the regression; they are two orders of magnitude smaller than the alphas relative to the CAPM. Not surprisingly, the loading on the HML factor increases in the decile; growth portfolios have a negative loading on the HML factor, while value portfolios have a positive loading.

The final panel of Table 8 compares the unconditional correlations of the portfolios with the stochastic discount factor, the shock to dividends, the shock to expected dividend growth orthogonal to dividend growth, and the shock to the preference variable. The correlation with the stochastic discount factor is lower, the greater the decile. This is consistent with the result that the Sharpe ratio increases in the decile; it follows from the unconditional Euler equation that the lower the correlation with the stochastic discount factor, the higher the Sharpe ratio.

As Table 8 shows, returns on value and growth portfolios correlate differently with shocks to the economy. Value stocks have the highest correlations with shocks to dividend growth (correlations range from .11 for the extreme growth portfolio to .26 for the extreme value portfolio). In contrast, growth stocks have a higher correlation with the independent component of the shock to expected dividend growth (correlations range from .21 for the extreme growth portfolio to .17 for the extreme value portfolio). While a shock to expected dividend 
growth raises the valuation of all portfolios, (as in the present value models of Campbell and Shiller (1988) and Vuolteenaho (2002)), it especially affects the valuations of growth stocks, which pay dividends in the distant future. Finally, all portfolios are negatively correlated with shocks to the Sharpe ratio variable $x_{t}$. A positive shock to $x_{t}$ raises expected returns, and thus lowers prices and realized returns. Growth stocks are more negatively correlated with $x_{t}$ than value stocks (correlations range from -.41 for the extreme growth portfolio to .29 for the extreme value portfolio). This is because of duration; growth stocks pay dividends further in the future, and thus are impacted more by a shock to expected returns.

This section has shown that the model replicates the principle aspects of the value premium in the data: value stocks have high expected returns, low volatility, high Sharpe ratios, high alphas, and low betas, relative to growth stocks. Value and growth stocks also differ in their correlations with the underlying shocks to the economy. As the next section shows, these differences in correlations are at the root of the model's ability to explain the value premium.

\section{Model Intuition}

What explains the model's ability to capture the value premium? As hinted in the previous section, the value premium arises from the differential correlations of value and growth portfolios on underlying shocks.

Figure 8 presents another look at this issue. Rather than correlations, Figure 8 contains betas from unconditional regressions of portfolio returns on the three shocks, and the $R^{2}$ from the unconditional regressions. Three results are apparent. First, $\beta_{d}$ is positive and increasing as the portfolios go from growth to value, second $\beta_{z}$ is positive and decreasing as portfolios go from growth to value, and $\beta_{x}$ is negative and increasing as firms go from growth to value. The $R^{2}$ s follow the same direction as the absolute value of the betas. It should not be surprising that the $R^{2}$ s fail to sum to 1 . The three shocks account for $100 \%$ of the conditional variance of returns. Figure 8, however, plots the results from unconditional regressions.

The results in Figure 8 arise from the different loadings of zero-coupon equity on the underlying shocks. As (15) shows, the loadings of returns on shocks to $x$ and $z$ is determined by $B_{x}$ and $B_{z}$ (the loadings on the shock to $d$ is always the same conditionally). For the 
parameter values we estimate, $B_{z}$ is positive and increasing in the maturity $n$ while $B_{x}$ is negative, and first decreases, and then, at high maturities, increases in $n$ (Figure 1). In the case of $B_{z}$ the increase occurs because long-horizon dividend growth matters more for assets that pay dividends in the future; for $B_{x}$, the pattern is accounted for by the duration effect, and because the risk price on expected dividend growth is negative. The intuition for these patterns is explained further in Sections 3 and 4.3.

The loadings on $z_{t}$ for zeros is echoed for portfolios. For high price-dividend firms (growth firms), the share of aggregate dividends is increasing. These firms place greater weight on higher-maturity equity than on lower-maturity equity. Thus their returns load more on $B_{z}$ than the returns of value firms, which place more weight on lower maturity equity. The loadings on $x_{t}$ are a bit different for portfolios than for zero-coupon equity. There is no evidence of the non-monotonicity seen in Figure 1. This is because, all else equal, equity that pays further in the future is worth less. Medium-horizon equity may therefore have a greater weight than long-horizon equity, even for growth firms. The non-monotonicity in $B_{x}$ occurs sufficiently far out in the equity term structure that it does not appear in the loadings of portfolios.

The loadings of portfolios on various shocks present an intriguing link with the empirical results of Campbell and Vuolteenaho (2003). Using the vector auto-regression methodology of Campbell (1991), Campbell and Vuolteenaho decompose unexpected market returns into changes in expectations of future discount rates and changes in expectations of future dividend growth rates. Changes in expected discount rates are computed using the vector auto-regression; changes in expected growth rates are the residual: the variation in market returns not explained by variation in discount rates. When the market return is decomposed in this way, Campbell and Vuolteenaho show that betas with respect to changes in expected discount rates decrease in magnitude as portfolios go from growth to value, while betas with respect to cash flows increase in magnitude as portfolios go from growth to value.

While not precisely analogous, shocks to $x_{t}$ are similar in spirit to news about discount rates in the VAR framework of Campbell and Vuolteenaho (2003). It is therefore encouraging that our model produces betas with respect to shocks to $x_{t}$ that are greater in magnitude for growth firms than value firms. The analogue to the dividend news term is less clear in our model. Campbell and Vuolteenaho compute this as a residual, though in our model Figure 8 shows that the residual variance is not accounted for by shocks to current or expected future 
dividends. More of the residual is accounted for by $\Delta d_{t+1}$ than by shocks to $z_{t+1}$; thus it is also encouraging that value portfolios load more on $\Delta d_{t+1}$ than growth portfolios.

Figure 8 shows that value and growth portfolios have different loadings on the underlying shocks in the economy. How this translates into risk premia depends on the prices of risk of these shocks. Equation (16) provides an illustration of how conditional risk premia on zero-coupon equity vary based on loadings on different shocks. As discussed in Section 4.1 we estimate that shocks to expected dividend growth $z_{t}$ are negatively correlated with shocks to realized dividend growth, based on dividend and consumption data. This empirical result implies that expected dividend growth has a negative risk price; because it is negatively correlated with shocks to realized dividend growth it serves as a hedge and reduces risk premia.

We assume that shocks to $x_{t}$ carry a zero risk price; shocks to $x_{t}$ are assumed to be uncorrelated with shocks to realized dividends or expected dividend growth. This assumption represents a departure from the models of Campbell and Cochrane (1999) and Menzly, Santos, and Veronesi (2004), where shocks to the price of risk are, conditionally, perfectly negatively correlated with shocks to aggregate dividends. What role does this assumption play in our analysis?

To answer this question, consider the equation for the conditional risk premium for equity that matures next period, versus the conditional risk premium for equity that matures two periods from now. By (16), equity that matures next period has a risk premium of

$$
\ln E_{t}\left[R_{1, t+1} / R^{f}\right]=\left\|\sigma_{d}\right\| x_{t}
$$

Equity that matures two periods from now has a risk premium of

$$
\ln E_{t}\left[R_{2, t+1} / R^{f}\right]=\left(1-\rho_{d x}\left\|\sigma_{x}\right\|+\rho_{d z} \frac{\left\|\sigma_{z}\right\|}{\left\|\sigma_{d}\right\|}\right)\left\|\sigma_{d}\right\| x_{t},
$$

where

$$
\rho_{d x}=\frac{\sigma_{d} \sigma_{x}^{\prime}}{\left\|\sigma_{d}\right\|\left\|\sigma_{x}\right\|}
$$

represents the conditional correlation between $\Delta d_{t+1}$ and $x_{t+1}$, and

$$
\rho_{d z}=\frac{\sigma_{d} \sigma_{z}^{\prime}}{\left\|\sigma_{d}\right\|\left\|\sigma_{z}\right\|}
$$

represents the conditional correlation between $\Delta d_{t+1}$ and $z_{t+1}$. The risk premium on equity that matures next period is equal to the quantity of risk - the standard deviation of dividends 
- multiplied by the price of risk $x_{t}$. For equity maturing two periods from now, there is also the risk due to changes in $x_{t}$ and changes in $z_{t}$. The latter effect will be relatively small because $\sigma_{z}$ is a small fraction of $\sigma_{d}$. Whether long-horizon equity has a lower risk premium than short-horizon equity is due in large part to the sign of the correlation of dividend growth with $x_{t}$. In particular, $\rho_{d x}<0$ leads to relatively higher premia for long-horizon equity, while $\rho_{d x}>0$ leads to relatively lower premia for long-horizon equity.

We make this statement precise by solving the model under three different possibilities for $\rho_{d x}$. Figure 7 plots risk premia on zero-coupon equity when $\rho_{d x}=0$ (our base case), $\rho_{d x}=-.5$, and $\rho_{d x}=.5$. For $\rho_{d x}=0$, Panel A shows that risk premia decrease in maturity, as long as $x_{t}>0$ (as it is most of the time). The reason for this decrease is the negative correlation between $\Delta d_{t+1}$ and $z_{t+1}$. In contrast, for $\rho_{d x}=-.5$, Panel B shows that risk premia generally increase in the maturity. Long-horizon equity (i.e. growth stocks) have greater risk premia than short-horizon equity. This occurs even though $\rho_{d z}$ is negative, as in Panel A. Even a modest correlation of - .5 between dividends and the price-of-risk overrides the effect of $\rho_{d z}$. The case of $\rho_{d x}<0$ is of special interest because it corresponds to the correlation between the price of risk and aggregate dividends in external habit models. In the models of Campbell and Cochrane (1999) and Menzly, Santos, and Veronesi (2004), shocks to the aggregate dividend (which is identified with consumption) increase surplus consumption, and therefore lower the amount of return investors demand for taking on risk. Indeed, in a term structure context, Wachter (2003) shows that the model of Campbell and Cochrane (1999) implies that long-horizon assets exhibit greater risk premia than short horizon assets for exactly this reason. Long-horizon assets load more negatively on the shock to discount rates; if discount rates are negatively correlated with consumption (or dividends) then long-horizon assets will command greater risk premia.

An alternative is to set the correlation between $d_{t+1}$ and $x_{t+1}$ to be positive. This case is illustrated in Panel C. Under this assumption, risk premia fall more dramatically in the maturity than when $d_{t+1}$ and $x_{t+1}$ are uncorrelated and the premium for short-horizon equity is greater.

These results at first suggest that a model that seeks to explain the value premium should set $\rho_{d x}>0$, rather than $\rho_{d x}=0$ as we assume. However, the sign of $\rho_{d x}$ has time series implications as well as cross-sectional ones. We are able to calibrate our model to match the time series of aggregate stock returns, as well the cross-section of value and growth portfolios 
because our model produces reasonable risk premia in the aggregate. For $\rho_{d x}>0$, this may not be the case. Figure 7 shows that the greater is $\rho_{d x}$, the lower are risk premia in the economy, for all but the shortest-maturity equity. As an asset that pays cash flows in the future, equity must load negatively on $x_{t}$. If investors view $x_{t}$-risk as a hedge $\left(\rho_{d x}>0\right)$, this makes equity less risky. On the other hand, if $x_{t}$ moves in the same direction as dividends $\left(\rho_{d x}<0\right)$, equity becomes more risky. Explaining the level of the equity premium is therefore easiest when $\rho_{d x}<0$ and hardest when $\rho_{d x}>0$. The assumption that $\rho_{d x}<0$ is part of what enables Campbell and Cochrane (1999) and Menzly, Santos, and Veronesi (2004) to explain the high variance and the high premium commanded by stock returns, with comparatively little variance in fundamentals. Faced with this tension between the time series and the cross section, we choose to set the correlation between dividend growth and $x_{t}$ at zero.

This section has shown that $\rho_{d x}$, in combination with the duration effect and the correlation between current and future dividend growth, makes long-horizon equity less risky than short-horizon equity. It creates a large premium on value stocks, while at the same time limiting their risk. We hope that future work will reveal micro-economic foundations that determine this important parameter.

\section{Conclusion}

This paper has proposed a parsimonious model of the stochastic discount factor that accounts for both the aggregate time series behavior of the stock market, and for the relative risk and return of value and growth stocks. At the root of the model is a dividend process calibrated to match the aggregate dividend process in the data, and a stochastic discount factor with a single factor, $x_{t}$, proxying for investors' time-varying preference for risk. Time-varying preferences for risk allow the model to capture the excess volatility and return predictability found in the data. Our specification for $x_{t}$ allows for interpretable closed-forms solutions for asset prices and risk premia.

A key difference between our model and external habit models, which also feature timevarying preferences for risk, is that $x_{t}$ does not arise from fluctuations in aggregate dividends. This may seem like a small detail but it is key to the model's ability to explain how value stocks can have both higher returns and less risk than growth stocks. In our model, growth and value stocks differ based on the timing of their cash flows. Growth stocks have more of 
their cash flows in the future. They are high-duration assets, and thus their returns covary more with the price of risk $x_{t}$. We have shown that for growth stocks to have relatively low returns, it must be the case that investors do not fear shocks to $x_{t}$. This only occurs if the conditional correlation of the price of risk with dividend growth is zero or positive. We assume the correlation is zero. In contrast, external habit models assume a correlation of negative one. Shocks to the price of risk are feared as much, if not more, than shocks to cash flows.

Our proposed resolution of the value puzzle is risk-based. Value stocks, as short-horizon equity, vary more with fluctuations in cash flows - the fluctuations that investors fear the most. Growth stocks, as long-horizon equity, vary more with fluctuations in discount rates, which are independent of cash flows and which investors do not fear. As we have shown, such a resolution accounts for the time series behavior of the aggregate market, the relative returns of value and growth stocks, and the failure of the capital asset pricing model to explain these returns. 


\section{Appendix}

\section{A Including a Lower Bound in the Share Specification}

Including a lower bound in the share specifications (21) and (22)-(23) allows for a superior fit to the cross-section of price ratios. For a model with shares $s_{i}$, we can define a new share process $\hat{s}_{i}$ such that

$$
\hat{s}_{i}=\underline{\mathrm{s}}+s_{i}(1-N \underline{\mathrm{s}})
$$

where $N$ is the number of firms, and $0 \leq \underline{\mathrm{s}}<1 / N$. Then the sequence $\hat{s}_{1}, \ldots, \hat{s}_{N}$ is positive, sums to 1, and thus forms a well-defined share process. Moreover, $\underline{\mathrm{s}}$ will be a lower bound on the share of the aggregate dividend.

Figure 9 shows the results for linearly declining growth, when the share process has a lower bound of $\underline{\mathrm{s}}=0.1 \%$. This change implies fewer firms with very high growth rates, and fewer firms with higher price dividend ratios. The distribution of dividend growth and the distribution of price ratios provide a closer match to the data, as shown in Figure 9. Introducing a lower bound to the constant growth case has a similar effect, as shown in Figure 10. Tables 10 and 11 show that the behavior of the cross-section of returns is similar to the cases when there are no lower bound. Qualitatively, the effects are similar to the case where there is no lower bound. The alpha for the extreme value portfolio is $2.6 \%$ for the linear growth case, and $2.7 \%$ for the constant growth case, while the alpha for the extreme growth stocks is $-2.2 \%$ for the linear growth case and $-2.0 \%$ for the constant growth case.

\section{B Convergence of the Price-Dividend Ratio}

Because $x_{t}$ and $z_{t}$ can take on both positive and negative values, a necessary (but not sufficient) condition for (17) to converge for all values of $x_{t}$ and $z_{t}$ is that $B_{x}(n)$ and $B_{z}(n)$ approach finite values as $n \rightarrow \infty$. $B_{z}$ converges if and only if:

$$
\left|\phi_{z}\right|<1
$$

Let

$$
\lambda=\sigma_{d} /\left\|\sigma_{d}\right\|
$$

Assuming (24) holds, $B_{x}$ converges if and only if

$$
\left|\phi_{x}-\sigma_{x} \lambda\right|<1
$$


Given (24)

$$
\lim _{n \rightarrow \infty} B_{z}(n)=\frac{1}{1-\phi_{z}} \equiv \bar{B}_{z}
$$

Define $\bar{B}_{x}$ to be the solution to

$$
\bar{B}_{x}=\bar{B}_{x}\left(\phi_{x}-\sigma_{x} \lambda\right)-\left(\sigma_{d}+\frac{\sigma_{z}}{1-\phi_{z}}\right) \lambda
$$

Then

$$
\bar{B}_{x}=-\frac{\left(\sigma_{d}+\sigma_{z} /\left(1-\phi_{z}\right)\right) \lambda}{1-\left(\phi_{x}-\sigma_{x} \lambda\right)}
$$

Given (24) and (25), it follows that

$$
\lim _{n \rightarrow \infty} B_{x}(n)=\bar{B}_{x}
$$

and

$$
\lim _{n \rightarrow \infty} V_{n}=\sigma_{d}+\frac{\sigma_{z}}{1-\phi_{z}}+\bar{B}_{x} \sigma_{x} \equiv \bar{V}
$$

Finally, let

$$
\bar{A}=-r+g+\bar{B}_{x}\left(1-\phi_{x}\right) \bar{x}+\frac{1}{2} \bar{V} \bar{V}
$$

It follows from the recursion for $A_{n}$ that for $N$ sufficiently large

$$
A(n) \approx \bar{A} n+\text { constant }
$$

for $n \geq N$, and therefore

$$
\sum_{n=N}^{\infty} \exp \left\{A(n)+B_{z}(n) z_{t}+B_{x}(n) x_{t}\right\} \approx \exp \left\{\text { constant }+\bar{B}_{z} z_{t}+\bar{B}_{x} x_{t}\right\} \sum_{n=N}^{\infty} \exp \{\bar{A} n\} .
$$

It follows that necessary and sufficient conditions for convergence are (24), (25), and

$$
-r+g+\bar{B}_{x}\left(1-\phi_{x}\right) \bar{x}+\frac{1}{2} \bar{V} \bar{V}<0
$$




\section{References}

Adrian, Tobias, and Francesco Franzoni, 2002, Learning about beta: An explanation of the value premium, unpublished paper, MIT.

Ang, Andrew, and Joseph Chen, 2003, CAPM over the long run: 1926-2001, Working Paper, Columbia University and University of Southern California.

Ang, Andrew, and Jun Liu, 2003, How to discount cash flows with time-varying expected returns, forthcoming, Journal of Finance.

Ang, Andrew, and Monika Piazzesi, 2003, A no-arbitrage vector autoregression of term structure dynamics with macroeconomic and latent variables, Journal of Monetary Economics $50,745-787$.

Bakshi, Gurdip S., and Zhiwu Chen, 1996, Inflation, asset prices, and the term structure of interest rates in a monetary economy, Review of Financial Studies 9, 241-275.

Ball, R., 1978, Anomolies in relationships between securities' yields and yield-surrogates, Journal of Financial Economics 6, 103-126.

Bansal, Ravi, Robert F. Dittmar, and Christian T. Lundblad, 2003, Interpreting risk premia across size, value, and industry portfolios, Working Paper, Duke University, Indiana University, and University of Michigan.

Bansal, Ravi, and Amir Yaron, 2003, Risks for the Long-Run: A Potential Resolution of Asset Pricing Puzzles, Journal of Finance, forthcoming.

Basu, Sanjoy, 1977, The Investment Performance of Common Stocks in Relation to Their Price to Earnings Ratios: A Test of the Efficient Market Hypothesis, Journal of Finance $32,663-82$.

Basu, Sanjoy, 1983, The relationship between earnings yield, market value, and return for NYSE common stocks: Further Evidence, Journal of Financial Economics 12, 129-156.

Bekaert, Geert, Eric Engstrom, and Steve Grenadier, 2004, Stock and bond returns with moody investors, Working paper, Columbia University, Stanford University, and University of Michigan. 
Berk, Jonathan B., Richard C. Green, and Vasant Naik, 1999, Optimal investment, growth options, and security returns, Journal of Finance 54, 1553-1607.

Bernstein, Richard, and Bernard Tew, 1991, The equity 'yield curve', Journal of Portfolio Management pp. 35-39.

Brennan, Michael J., Ashley W. Wang, and Yihong Xia, 2003, Estimation and test of a simple model of intertemporal asset pricing, forthcoming, Journal of Finance.

Brennan, Michael J., and Yihong Xia, 2003, Risk and valuation under an intertemporal capital asset pricing model, forthcoming, Journal of Business.

Campbell, John Y., 1991, A Variance Decomposition for Stock Returns, Economic Journal $101,157-179$.

Campbell, John Y., 1999, Asset prices, consumption, and the business cycle, in J.B. Taylor, and M. Woodford, eds.: Handbook of Macroeconomics, Volume I (North-Holland, Amsterdam ).

Campbell, John Y., and John H. Cochrane, 1999, By force of habit: A consumption-based explanation of aggregate stock market behavior, Journal of Political Economy 107, 205251.

Campbell, John Y., and Jianping Mei, 1993, Where do betas come from? Asset pricing dynamics and the sources of systematic risk, Review of Financial Studies 6, 567-592.

Campbell, John Y., Christopher Polk, and Tuomo Vuolteenaho, 2003, Growth or glamour?, Working Paper, Harvard University and Northwestern University.

Campbell, John Y., and Robert J. Shiller, 1988, The dividend-price ratio and expectations of future dividends and discount factors, Review of Financial Studies 58, 495-514.

Campbell, John Y., and Tuomo Vuolteenaho, 2003, Bad beta, good beta, Working Paper, Harvard University.

Cochrane, John H., 1992, Explaining the variance of price-dividend ratios, Review of Financial Studies 5, 243-280. 
Cochrane, John H., 1999, New facts in finance, Economic Perspectives Federal Reserve Bank of Chicago 23, 59-78.

Cohen, Randolph B., Christopher Polk, and Tuomo Vuolteenaho, 2002, Does risk or mispricing explain the cross-section of stock prices?, Working Paper, Harvard University and Northwestern University.

Cohen, Randolph B., Christopher Polk, and Tuomo Vuolteenaho, 2003, The value spread, Journal of Finance 58, 609-641.

Cornell, Bradford, 1999, Risk, duration, and capital budgeting: New evidence on some old questions, Journal of Business 72, 183-200.

Dai, Qiang, and Kenneth Singleton, 2003, Term structure dynamics in theory and reality, Review of Financial Studies 16, 631-678.

Dechow, Patricia M., Richard G. Sloan, and Mark T. Soliman, 2002, Implied equity duration: A new measure of equity risk, Working Paper, University of Michigan.

Duffee, Gregory R., 2002, Term premia and interest rate forecasts in affine models, Journal of Finance 57, 369-443.

Duffie, Darrell, and Rui Kan, 1996, A yield-factor model of interest rates, Mathematical Finance 6, 379-406.

Fama, Eugene F., and Kenneth R. French, 1989, Business conditions and expected returns on stocks and bonds, Journal of Financial Economics 29, 23-49.

Fama, Eugene F., and Kenneth R. French, 1992, The Cross-Section of Expected Returns, Journal of Finance 47, 427-465.

Fama, Eugene F., and Kenneth R. French, 1995, Size and book-to-market factors in earnings and returns, Journal of Finance 50, 131-155.

Gomes, Joao, Leonid Kogan, and Lu Zhang, 2003, Equilibrium Cross Section of Returns, Journal of Political Economy 111, 693-732. 
Graham, Benjamin, and David L. Dodd, 1934, Security Analysis. (McGraw Hill New York) 1 edn.

Jaffe, Jeffrey, Donald B. Keim, and Randolph Westerfield, 1989, Earnings yields, market values, and stock returns, The Journal of Finance 44, 134-148.

Jagannathan, Ravi, and Zhenyu Wang, 1996, The Conditional CAPM and the Cross-Section of Expected Returns, Journal of Finance 51, 3-54.

Johnson, Timothy C., 2002, Rational momentum effects, Journal of Finance 57, 585-608.

Keim, Donald B., and Robert F. Stambaugh, 1986, Predicting returns in the stock and bond markets, Journal of Financial Econometrics 17, 357-390.

Leibowitz, Martin L., and Stanley Kogelman, 1993, Resolving the equity duration paradox, Financial Analysts Journal pp. 51-64.

Lettau, Martin, and Sydney C. Ludvigson, 2001, Resurrecting the (C)CAPM: A CrossSectional Test When Risk Premia are Time-Varying, Journal of Political Economy 109, $1238-1287$.

Lettau, Martin, and Sydney C. Ludvigson, 2002, Expected Returns and Expected Dividend Growth, NBER Working Paper No. 9605.

Lewellen, Jonathan, and Jay Shanken, 2002, Learning, asset-pricing tests, and market efficiency, Journal of Finance 57, 1113-1145.

Liew, Jimmy, and Maria Vassalou, 2000, Can Book-to-Market, Size and Momentum Be Risk Factors that Predict Economic Growth?, Journal of Financial Economics 57, 221-245.

Lintner, J., 1965, Security Prices, Risk and Maximal Gains from Diversification, Journal of Finance 20, 587-615.

Lustig, Hanno, and Stijn VanNieuwerburgh, 2002, Housing Collateral, Consumption Insurance and Risk Premia, Working Paper, University of Chicago.

Lynch, Anthony W., 2003, Portfolio choice with many risky assets, market clearing, and cash-flow predictability, Working Paper, New York University. 
Menzly, Lior, Tano Santos, and Pietro Veronesi, 2004, Understanding Predictability, Journal of Poitical Economy 112, 1-47.

Parker, Jonathan A., and Christian Julliard, 2005, Consumption risk and the cross section of expected returns, Journal of Political Economy 113.

Piazzesi, Monika, Martin Schneider, and Selale Tuzel, 2002, Housing, Consumption, and Asset Pricing, Working Paper, UCLA.

Rosenberg, Barr, Kenneth Reid, and Ronald Lanstein, 1985, Persuasive evidence of market inefficiency, Journal of Portfolio Management 11, 9-17.

Santos, Tano, and Pietro Veronesi, 2004, Conditional betas, Working Paper, Columbia University and University of Chicago.

Sharpe, W., 1964, Capital Asset Prices: A Theory of Market Equilibrium under Conditions of Risk, Journal of Finance 19, 425-444.

Vassalou, Maria, 2003, News related to future GDP growth as a risk factor in equity returns, Journal of Financial Economics 68, 47-73.

Vuolteenaho, Tuomo, 2002, What drives firm-level stock returns?, Journal of Finance 57, 233-264.

Wachter, Jessica A., 2003, A consumption-based model of the term structure of interest rates, Working paper, University of Pennsylvania.

Wilson, Mungo, 2003, A model of demand for dividend strips, Working Paper, Harvard University.

Yogo, Motohiro, 2003, A Consumption-Based Explanation of the Cross Section of Expected Stock Returns, Working Paper, Harvard University.

Zhang, Lu, 2005, The value premium, Journal of Finance 60, 67-103.

Zhang, Lu, and Ralitsa Petkova, 2002, Is value riskier than growth?, Working Paper, University of Rochester. 
Table 1: Data Moments of Growth and Value Portfolios

\begin{tabular}{|c|c|c|c|c|c|c|c|c|c|c|c|}
\hline \multirow[b]{2}{*}{ Portfolio } & \multirow{2}{*}{$\begin{array}{l}\mathrm{G} \\
1 \\
\end{array}$} & \multicolumn{7}{|c|}{ Growth to Value } & \multirow{2}{*}{\multicolumn{2}{|c|}{$\begin{array}{c}\mathrm{V} \\
10 \\
\end{array}$}} & \multirow{2}{*}{$\begin{array}{c}\text { V-G } \\
10-1\end{array}$} \\
\hline & & 2 & 3 & 4 & 5 & 6 & 7 & 8 & & & \\
\hline \multicolumn{12}{|c|}{ Mean Excess Return (\% per year) } \\
\hline $\mathrm{E} / \mathrm{P}$ & 4.71 & 5.02 & 6.97 & 7.04 & 7.00 & 9.18 & 9.94 & 11.18 & 11.68 & 12.95 & 8.25 \\
\hline $\mathrm{C} / \mathrm{P}$ & 5.05 & 6.07 & 6.49 & 6.73 & 8.48 & 7.72 & 8.85 & 9.18 & 11.47 & 11.81 & 6.77 \\
\hline $\mathrm{D} / \mathrm{P}$ & 7.35 & 6.41 & 7.28 & 7.41 & 6.49 & 7.60 & 7.73 & 9.49 & 8.84 & 7.45 & 0.10 \\
\hline $\mathrm{B} / \mathrm{M}$ & 5.67 & 6.55 & 6.98 & 6.51 & 8.00 & 8.33 & 8.27 & 10.08 & 9.98 & 10.55 & 4.88 \\
\hline \multicolumn{12}{|c|}{ Standard Error of Mean } \\
\hline $\mathrm{E} / \mathrm{P}$ & 0.78 & 0.64 & 0.62 & 0.59 & 0.62 & 0.61 & 0.60 & 0.61 & 0.65 & 0.73 & 0.62 \\
\hline $\mathrm{C} / \mathrm{P}$ & 0.76 & 0.64 & 0.61 & 0.63 & 0.62 & 0.60 & 0.60 & 0.60 & 0.61 & 0.69 & 0.59 \\
\hline $\mathrm{D} / \mathrm{P}$ & 0.78 & 0.69 & 0.66 & 0.64 & 0.62 & 0.60 & 0.59 & 0.58 & 0.56 & 0.56 & 0.69 \\
\hline $\mathrm{B} / \mathrm{M}$ & 0.71 & 0.64 & 0.64 & 0.62 & 0.59 & 0.59 & 0.59 & 0.61 & 0.63 & 0.74 & 0.61 \\
\hline \multicolumn{12}{|c|}{ Standard Deviation of Excess Return (\% per year) } \\
\hline $\mathrm{E} / \mathrm{P}$ & 19.35 & 15.93 & 15.49 & 14.78 & 15.43 & 15.04 & 14.87 & 15.29 & 16.11 & 18.11 & 15.40 \\
\hline $\mathrm{C} / \mathrm{P}$ & 18.99 & 15.95 & 15.24 & 15.75 & 15.43 & 14.95 & 14.96 & 14.98 & 15.14 & 17.24 & 14.57 \\
\hline $\mathrm{D} / \mathrm{P}$ & 19.36 & 17.11 & 16.31 & 15.85 & 15.43 & 15.00 & 14.58 & 14.37 & 13.93 & 13.83 & 17.08 \\
\hline $\mathrm{B} / \mathrm{M}$ & 17.77 & 15.89 & 15.82 & 15.42 & 14.65 & 14.73 & 14.74 & 15.11 & 15.71 & 18.46 & 15.15 \\
\hline \multicolumn{12}{|c|}{ Sharpe Ratio } \\
\hline $\mathrm{E} / \mathrm{P}$ & 0.24 & 0.32 & 0.45 & 0.48 & 0.45 & 0.61 & 0.67 & 0.73 & 0.73 & 0.72 & 0.54 \\
\hline $\mathrm{C} / \mathrm{P}$ & 0.27 & 0.38 & 0.43 & 0.43 & 0.55 & 0.52 & 0.59 & 0.61 & 0.76 & 0.69 & 0.46 \\
\hline $\mathrm{D} / \mathrm{P}$ & 0.38 & 0.37 & 0.45 & 0.47 & 0.42 & 0.51 & 0.53 & 0.66 & 0.63 & 0.54 & 0.01 \\
\hline $\mathrm{B} / \mathrm{M}$ & 0.32 & 0.41 & 0.44 & 0.42 & 0.55 & 0.57 & 0.56 & 0.67 & 0.64 & 0.57 & 0.32 \\
\hline
\end{tabular}

Notes: Summary statistics for 10 growth to value portfolios. "D/P" are deciles computed from sorting firms based on their dividend yields, "E/P" are sorts based on the earnings yields, "C/P" are sorts based on the ratio of cash flows to price and "B/M" are sorts on the book-to-market ratio. All data are from Ken French's website. The data are monthly and span the 1952 to 2002 period. 
Table 2: Correlation of Growth and Value Portfolios

\begin{tabular}{|c|c|c|c|c|}
\hline & $\mathrm{D} / \mathrm{P}$ & $\mathrm{E} / \mathrm{P}$ & $\mathrm{C} / \mathrm{P}$ & $\mathrm{B} / \mathrm{M}$ \\
\hline \multicolumn{5}{|c|}{ Top Growth Decile } \\
\hline $\mathrm{E} / \mathrm{P}$ & 1.00 & 0.98 & 0.93 & 0.96 \\
\hline $\mathrm{C} / \mathrm{P}$ & 0.98 & 1.00 & 0.93 & 0.97 \\
\hline $\mathrm{D} / \mathrm{P}$ & 0.93 & 0.93 & 1.00 & 0.94 \\
\hline $\mathrm{B} / \mathrm{M}$ & 0.96 & 0.97 & 0.94 & 1.00 \\
\hline \multicolumn{5}{|c|}{ Top Value Decile } \\
\hline $\mathrm{E} / \mathrm{P}$ & 1.00 & 0.94 & 0.76 & 0.85 \\
\hline $\mathrm{C} / \mathrm{P}$ & 0.94 & 1.00 & 0.74 & 0.85 \\
\hline $\mathrm{D} / \mathrm{P}$ & 0.76 & 0.74 & 1.00 & 0.75 \\
\hline $\mathrm{B} / \mathrm{M}$ & 0.85 & 0.85 & 0.75 & 1.00 \\
\hline
\end{tabular}

Notes: Correlations among growth and value portfolios formed from sorting on different variables. "D/P" are deciles computed from sorting firms based on their dividend yields, "E/P" are sorts based on the earnings yields, "C/P" are sorts based on the ratio of cash flows to price and "B/M" are sorts on the book-to-market ratio. All data are from Ken French's website. The data are monthly and span the 1952 to 2002 period. 
Table 3: Performance of Growth and Value Portfolios Relative to the CAPM

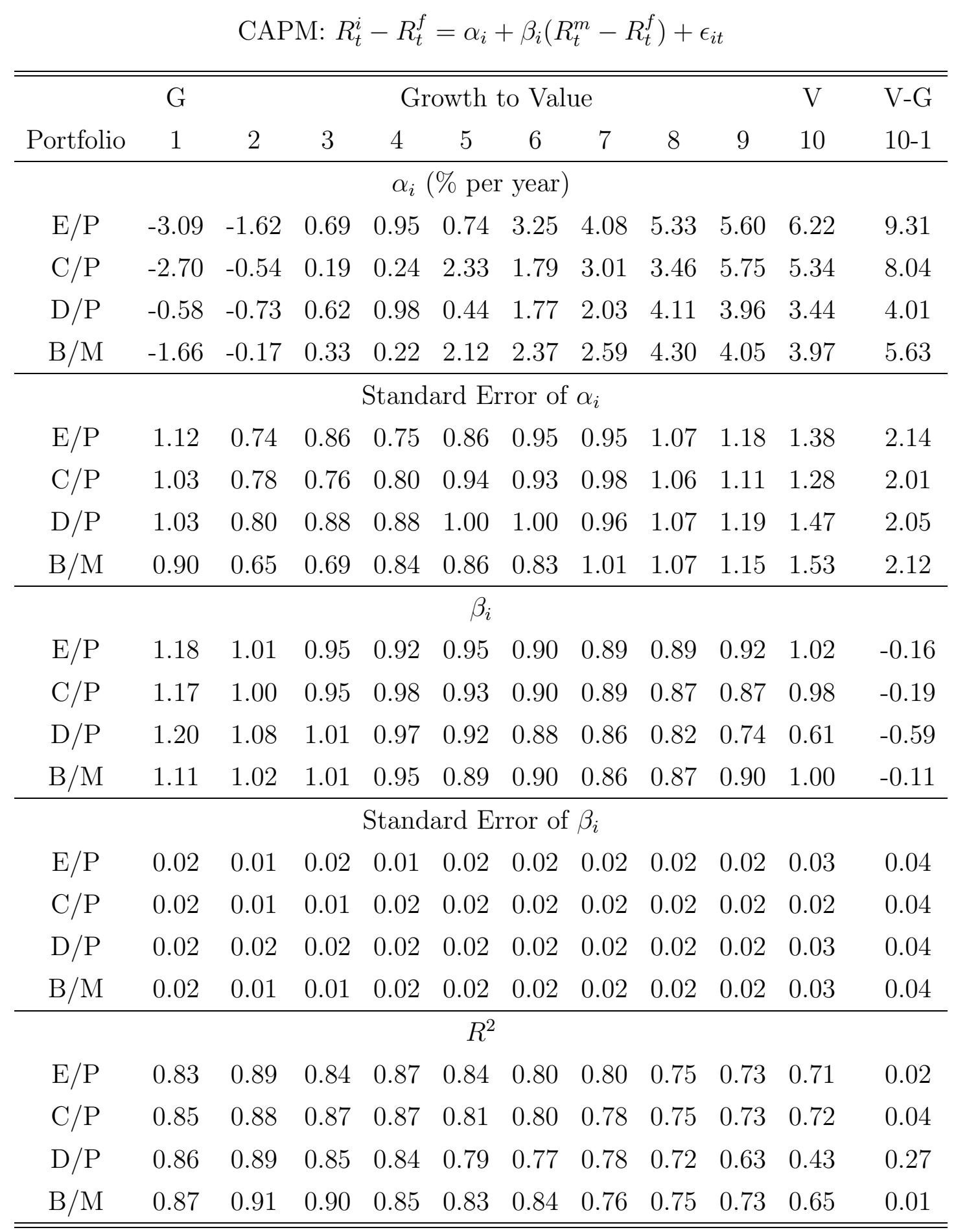

Notes: Estimates from CAPM regressions of 10 growth to value deciles. "D/P" are deciles computed from sorting firms based on their dividend yields, "E/P" are sorts based on the earnings yields, " $\mathrm{C} / \mathrm{P}$ " are sorts based on the ratio of cash flows to price and " $\mathrm{B} / \mathrm{M}$ " are sorts on the book-to-market ratio. All data are from Ken French's website. The data are monthly and span the 1952 to 2002 period. 
Table 4: Parameters of the Model

$$
\begin{aligned}
\Delta d_{t+1} & =g+z_{t}+\sigma_{d} \epsilon_{t+1} \\
z_{t+1} & =\phi_{z} z_{t}+\sigma_{z} \epsilon_{t+1} \\
x_{t+1} & =\left(1-\phi_{x}\right) \bar{x}+\phi_{x} x_{t}+\sigma_{x} \epsilon_{t+1} \\
M_{t+1} & =\exp \left\{-r^{f}-\frac{1}{2} x_{t}^{2}-x_{t} \frac{\sigma_{d}}{\left\|\sigma_{d}\right\|} \epsilon_{t+1}\right\}
\end{aligned}
$$

\begin{tabular}{cc}
\hline \hline Variable & Value \\
\hline$g$ & $2.28 \%$ \\
$r_{f}$ & $1.93 \%$ \\
$\bar{x}$ & 0.625 \\
$\phi_{z}$ & 0.91 \\
$\phi_{x}$ & 0.87 \\
$\left\|\sigma_{d}\right\|$ & 0.145 \\
$\left\|\sigma_{z}\right\|$ & 0.0016 \\
$\left\|\sigma_{x}\right\|$ & 0.24 \\
Correlation of $\Delta d$ and $z$ shocks & -0.83 \\
Correlation of $\Delta d$ and $x$ shocks & 0 \\
Correlation of $z$ and $x$ shocks & 0 \\
\hline \hline
\end{tabular}

Implied volatility parameters

\begin{tabular}{cc}
\hline Variable & Values \\
\hline$\sigma_{d}$ & {$[0.0724,0,0]$} \\
$\sigma_{z}$ & {$[-0.0013,0.0009,0]$} \\
$\sigma_{z}$ & {$[0,0,0.12]$} \\
\hline \hline
\end{tabular}

Notes: Model parameters are calibrated to aggregate data starting in 1890 and ending in 2002. The model is simulated at a quarterly frequency. The unconditional mean of dividend growth $g$, the riskfree rate $r_{f}$, the persistence variables $\phi_{x}$ and $\phi_{z}$, and the conditional standard deviations $\left\|\sigma_{d}\right\|,\left\|\sigma_{d}\right\|,\left\|\sigma_{d}\right\|$, are in annual terms (i.e. $4 g, \phi_{x}^{4}, 2\left\|\sigma_{d}\right\|$ ). Parameters $g$, $r_{f}$, and $\left\|\sigma_{d}\right\|$ are set to match their data counterparts. Parameters $\phi_{z}$ and the correlation between shocks to $z$ and shocks to $\Delta d$ are set to match their data counterparts, assuming that the the conditional mean of dividend growth is the log of the consumption-dividend ratio in the data. 
Table 5: Aggregate Asset Pricing Implications

\begin{tabular}{ccc}
\hline \hline & Data & Model \\
\hline$E(P / D)$ & 25.55 & 20.96 \\
$\sigma(p-d)$ & 0.38 & 0.38 \\
$\mathrm{AC}$ of $p-d$ & 0.87 & 0.88 \\
$E\left[R^{m}-R^{f}\right]$ & $6.33 \%$ & $7.87 \%$ \\
$\sigma\left(R^{m}-R^{f}\right)$ & $19.41 \%$ & $19.19 \%$ \\
$\mathrm{AC}$ of $R^{m}-R^{f}$ & 0.03 & -0.04 \\
Sharpe ratio of market & 0.33 & 0.41 \\
$\mathrm{AC}$ of $\Delta d$ & -0.09 & -0.04 \\
$\sigma\left(\Delta d_{t}\right)$ & $14.48 \%$ & $14.43 \%$ \\
\hline \hline
\end{tabular}

Notes: Aggregate moments implied by the parameter values in Table 4. The model is simulated for 50,000 quarters and returns, dividends, and price ratios are aggregated to an annual frequency. The data are annual, start in 1890, and end in 2002. 
Table 6: Long Horizon Regressions - Excess Returns

\begin{tabular}{|c|c|c|c|c|c|c|}
\hline \multicolumn{7}{|c|}{ Horizon in Years } \\
\hline & 1 & 2 & 4 & 6 & 8 & 10 \\
\hline \multicolumn{7}{|c|}{$\sum_{i=1}^{H} r_{t+i}^{m}-r_{t+i}^{f}=\beta_{0}+\beta_{1}\left(p_{t}-d_{t}\right)+\epsilon_{t}$} \\
\hline \multicolumn{7}{|c|}{ Data } \\
\hline$\beta_{1}$ & -0.12 & -0.23 & -0.37 & -0.60 & -0.86 & -1.09 \\
\hline$t$-stat & $(-2.39)$ & $(-2.44)$ & $(-2.01)$ & $(-2.24)$ & $(-2.97)$ & $(-3.54)$ \\
\hline$R^{2}$ & {$[0.05]$} & {$[0.08]$} & {$[0.10]$} & {$[0.16]$} & {$[0.25]$} & {$[0.31]$} \\
\hline \multicolumn{7}{|c|}{ Data up to 1994} \\
\hline$\beta_{1}$ & -0.21 & -0.39 & -0.61 & -0.89 & -1.16 & -1.34 \\
\hline$t$-stat & $(-3.45)$ & $(-4.04)$ & $(-3.17)$ & $(-4.08)$ & $(-5.81)$ & $(-6.22)$ \\
\hline$R^{2}$ & {$[0.07]$} & {$[0.13]$} & {$[0.19]$} & {$[0.30]$} & {$[0.41]$} & {$[0.44]$} \\
\hline \multicolumn{7}{|c|}{ Model } \\
\hline$\beta_{1}$ & -0.11 & -0.21 & -0.36 & -0.49 & -0.58 & -0.65 \\
\hline$R^{2}$ & {$[0.06]$} & {$[0.11]$} & {$[0.18]$} & {$[0.23]$} & {$[0.26]$} & {$[0.28]$} \\
\hline
\end{tabular}

Notes: Long-horizon regressions of excess returns on the price-dividend ratio in annual data from 1890-2002 and in data simulated from the model. For each data regression, the table reports OLS estimates of the regressors, Newey-West (1987) corrected $t$-statistics (in parentheses) and adjusted $R^{2}$ statistics in square brackets. Significant data coefficients using the standard $t$-test at the $5 \%$ level are highlighted in bold face. 
Table 7: Long Horizon Regressions - Dividend Growth

\begin{tabular}{|c|c|c|c|c|c|c|}
\hline \multicolumn{7}{|c|}{ Horizon in Years } \\
\hline & 1 & 2 & 4 & 6 & 8 & 10 \\
\hline \multicolumn{7}{|c|}{ Data } \\
\hline \multicolumn{7}{|c|}{$\sum_{i=1}^{H} \Delta d_{t+i}^{m}=\beta_{0}+\beta_{1}\left(p_{t}-d_{t}\right)+\epsilon_{t}$} \\
\hline $\begin{array}{c}\beta_{1} \\
t \text {-stat } \\
R^{2}\end{array}$ & $\begin{array}{c}0.02 \\
(0.56) \\
{[-0.01]}\end{array}$ & $\begin{array}{c}-0.01 \\
(-0.23) \\
{[-0.01]}\end{array}$ & $\begin{array}{l}-0.04 \\
(-0.34) \\
{[-0.01]}\end{array}$ & $\begin{array}{c}-0.12 \\
(-0.85) \\
{[0.00]}\end{array}$ & $\begin{array}{c}-0.23 \\
(-1.26) \\
{[0.02]}\end{array}$ & $\begin{array}{c}-0.31 \\
(-1.61) \\
{[0.05]}\end{array}$ \\
\hline \multicolumn{7}{|c|}{$\sum_{i=1}^{H} \Delta d_{t+i}^{m}=\beta_{0}+\beta_{1}\left(c_{t}-d_{t}\right)+\epsilon_{t}$} \\
\hline $\begin{array}{c}\beta_{1} \\
t \text {-stat } \\
R^{2} \\
\end{array}$ & $\begin{array}{c}\mathbf{0 . 1 0} \\
(2.30) \\
{[0.03]} \\
\end{array}$ & $\begin{array}{c}\mathbf{0 . 1 8} \\
(2.52) \\
{[0.06]} \\
\end{array}$ & $\begin{array}{c}\mathbf{0 . 3 4} \\
(3.05) \\
{[0.13]} \\
\end{array}$ & $\begin{array}{c}\mathbf{0 . 5 6} \\
(3.42) \\
{[0.24]} \\
\end{array}$ & $\begin{array}{c}\mathbf{0 . 6 5} \\
(3.56) \\
{[0.26]} \\
\end{array}$ & $\begin{array}{c}\mathbf{0 . 6 8} \\
(3.78) \\
{[0.25]} \\
\end{array}$ \\
\hline \multicolumn{7}{|c|}{ Model } \\
\hline \multicolumn{7}{|c|}{$\sum_{i=1}^{H} \Delta d_{t+i}^{m}=\beta_{0}+\beta_{1}\left(p_{t}-d_{t}\right)+\epsilon_{t}$} \\
\hline $\begin{array}{l}\beta_{1} \\
R^{2}\end{array}$ & $\begin{array}{c}0.05 \\
{[0.02]}\end{array}$ & $\begin{array}{c}0.09 \\
{[0.03]}\end{array}$ & $\begin{array}{c}0.17 \\
{[0.06]}\end{array}$ & $\begin{array}{c}0.24 \\
{[0.08]}\end{array}$ & $\begin{array}{c}0.29 \\
{[0.09]}\end{array}$ & $\begin{array}{c}0.33 \\
{[0.09]}\end{array}$ \\
\hline \multicolumn{7}{|c|}{$\sum_{i=1}^{H} \Delta d_{t+i}^{m}=\beta_{0}+\beta_{1} z_{t}+\epsilon_{t}$} \\
\hline $\begin{array}{l}\beta_{1} \\
R^{2}\end{array}$ & $\begin{array}{c}3.73 \\
{[0.04]}\end{array}$ & $\begin{array}{c}7.09 \\
{[0.07]}\end{array}$ & $\begin{array}{l}13.19 \\
{[0.13]}\end{array}$ & $\begin{array}{l}18.13 \\
{[0.18]}\end{array}$ & $\begin{array}{l}22.23 \\
{[0.21]}\end{array}$ & $\begin{array}{l}25.81 \\
{[0.24]}\end{array}$ \\
\hline
\end{tabular}

Notes: Long-horizon regressions for dividend growth in annual data from 1890-2002 and in data simulated from the model. For each data regression, the table reports OLS estimates of the regressors, Newey-West (1987) corrected $t$-statistics (in parentheses) and adjusted $R^{2}$ statistics in square brackets. Significant data coefficients using the standard $t$-test at the $5 \%$ level are highlighted in bold face. 
Table 8: Growth vs. Value Portfolios: Linear Growth

\begin{tabular}{|c|c|c|c|c|c|c|c|c|c|c|c|}
\hline & $\mathrm{G}$ & & & & Growth & to Valu & & & & $\mathrm{V}$ & $\mathrm{V}-\mathrm{G}$ \\
\hline Portfolio & 1 & 2 & 3 & 4 & 5 & 6 & 7 & 8 & 9 & 10 & $10-1$ \\
\hline$E R^{i}-R^{f}$ & 4.44 & 4.55 & 4.85 & 5.29 & 6.00 & 6.91 & 7.91 & 8.79 & 9.37 & 9.65 & 5.20 \\
\hline$\sigma\left(R^{i}-R^{f}\right)$ & 19.22 & 19.32 & 19.48 & 19.52 & 19.41 & 19.05 & 18.47 & 17.82 & 17.24 & 16.91 & 8.33 \\
\hline Sharpe Ratio & 0.23 & 0.24 & 0.25 & 0.27 & 0.31 & 0.36 & 0.43 & 0.49 & 0.54 & 0.57 & 0.62 \\
\hline \multicolumn{12}{|c|}{$\mathrm{CAPM}: R_{t}^{i}-R_{t}^{f}=\alpha_{i}+\beta_{i}\left(R_{t}^{m}-R_{t}^{f}\right)+\epsilon_{i t}$} \\
\hline$\alpha_{i}$ & -2.86 & -2.80 & -2.59 & -2.20 & -1.49 & -0.47 & 0.76 & 1.94 & 2.84 & 3.30 & 6.17 \\
\hline$\beta_{i}$ & 0.99 & 1.00 & 1.01 & 1.02 & 1.02 & 1.00 & 0.97 & 0.93 & 0.89 & 0.86 & -0.13 \\
\hline$R_{i}^{2}$ & 0.96 & 0.96 & 0.97 & 0.98 & 0.99 & 1.00 & 1.00 & 0.98 & 0.95 & 0.94 & 0.09 \\
\hline \multicolumn{12}{|c|}{ CAPM \& HML: $R_{t}^{i}-R_{t}^{f}=\alpha_{i}+\beta_{i}\left(R_{t}^{m}-R_{t}^{f}\right)+\gamma_{i} \mathrm{HML}_{t}+\epsilon_{i t}$} \\
\hline$\alpha_{i}$ & 0.04 & 0.03 & 0.03 & 0.02 & 0.02 & 0.01 & 0.01 & 0.02 & 0.03 & 0.04 & 0.00 \\
\hline$\beta_{i}$ & 0.93 & 0.94 & 0.95 & 0.97 & 0.99 & 0.99 & 0.99 & 0.97 & 0.95 & 0.93 & 0.00 \\
\hline$\gamma_{i}$ & -0.47 & -0.46 & -0.43 & -0.36 & -0.25 & -0.08 & 0.12 & 0.31 & 0.46 & 0.53 & 1.00 \\
\hline$R_{i}^{2}$ & 1.00 & 1.00 & 1.00 & 1.00 & 1.00 & 1.00 & 1.00 & 1.00 & 1.00 & 1.00 & 1.00 \\
\hline \multicolumn{12}{|c|}{ Unconditional Correlations } \\
\hline$\rho\left(R^{i}, M\right)$ & -0.08 & -0.08 & -0.09 & -0.09 & -0.11 & -0.12 & -0.14 & -0.16 & -0.18 & -0.19 & -0.19 \\
\hline$\rho\left(R^{i}, \epsilon^{1}\right)$ & 0.11 & 0.11 & 0.12 & 0.13 & 0.14 & 0.17 & 0.19 & 0.22 & 0.24 & 0.26 & 0.27 \\
\hline$\rho\left(R^{i}, \epsilon^{2}\right)$ & 0.21 & 0.21 & 0.21 & 0.20 & 0.19 & 0.19 & 0.18 & 0.18 & 0.17 & 0.17 & -0.14 \\
\hline$\rho\left(R^{i}, \epsilon^{3}\right)$ & -0.41 & -0.41 & -0.41 & -0.41 & -0.40 & -0.39 & -0.36 & -0.34 & -0.31 & -0.29 & 0.35 \\
\hline
\end{tabular}

Notes: Simulated return statistics for 10 portfolios formed according to price-dividend ratios.

Parameter values for the aggregate market are as in Table 4. The model is simulated at a quarterly frequency and returns are aggregated up to an annual frequency. Growth of the dividend shares is assumed to decline linearly from $75 \%$ p.a. to $-75 \%$ p.a. There is no lower bound for the dividend share. 
Table 9: Growth vs. Value Portfolios: Constant Growth

\begin{tabular}{|c|c|c|c|c|c|c|c|c|c|c|c|}
\hline & G & & & & Growth & to Valu & & & & $\mathrm{V}$ & $\mathrm{V}-\mathrm{G}$ \\
\hline Portfolio & 1 & 2 & 3 & 4 & 5 & 6 & 7 & 8 & 9 & 10 & $10-1$ \\
\hline$E R^{i}-R^{f}$ & 5.00 & 5.18 & 5.47 & 5.90 & 6.46 & 7.15 & 7.89 & 8.58 & 9.16 & 10.08 & 5.09 \\
\hline$\sigma\left(R^{i}-R^{f}\right)$ & 19.27 & 19.48 & 19.64 & 19.67 & 19.51 & 19.08 & 18.38 & 17.56 & 16.99 & 17.30 & 8.27 \\
\hline Sharpe Ratio & 0.26 & 0.27 & 0.28 & 0.30 & 0.33 & 0.37 & 0.43 & 0.49 & 0.54 & 0.58 & 0.62 \\
\hline \multicolumn{12}{|c|}{$\mathrm{CAPM}: R_{t}^{i}-R_{t}^{f}=\alpha_{i}+\beta_{i}\left(R_{t}^{m}-R_{t}^{f}\right)+\epsilon_{i t}$} \\
\hline$\alpha_{i}$ & -2.60 & -2.52 & -2.31 & -1.93 & -1.33 & -0.50 & 0.52 & 1.59 & 2.48 & 3.38 & 5.98 \\
\hline$\beta_{i}$ & 1.00 & 1.01 & 1.02 & 1.03 & 1.02 & 1.00 & 0.97 & 0.92 & 0.88 & 0.88 & -0.12 \\
\hline$R_{i}^{2}$ & 0.97 & 0.97 & 0.97 & 0.98 & 0.99 & 1.00 & 1.00 & 0.98 & 0.96 & 0.93 & 0.07 \\
\hline \multicolumn{12}{|c|}{ CAPM \& HML: $R_{t}^{i}-R_{t}^{f}=\alpha_{i}+\beta_{i}\left(R_{t}^{m}-R_{t}^{f}\right)+\gamma_{i} \mathrm{HML}_{t}+\epsilon_{i t}$} \\
\hline$\alpha_{i}$ & 0.05 & 0.04 & 0.02 & 0.01 & 0.01 & 0.01 & 0.03 & 0.05 & 0.06 & 0.05 & 0.00 \\
\hline$\beta_{i}$ & 0.95 & 0.96 & 0.98 & 0.99 & 1.00 & 0.99 & 0.98 & 0.95 & 0.93 & 0.95 & 0.00 \\
\hline$\gamma_{i}$ & -0.44 & -0.43 & -0.39 & -0.32 & -0.22 & -0.09 & 0.08 & 0.26 & 0.40 & 0.56 & 1.00 \\
\hline$R_{i}^{2}$ & 1.00 & 1.00 & 1.00 & 1.00 & 1.00 & 1.00 & 1.00 & 1.00 & 1.00 & 1.00 & 1.00 \\
\hline \multicolumn{12}{|c|}{ Unconditional Correlations } \\
\hline$\rho\left(R^{i}, M\right)$ & -0.06 & -0.06 & -0.06 & -0.07 & -0.08 & -0.09 & -0.10 & -0.12 & -0.14 & -0.15 & -0.19 \\
\hline$\rho\left(R^{i}, \epsilon^{1}\right)$ & 0.09 & 0.09 & 0.10 & 0.11 & 0.12 & 0.14 & 0.17 & 0.19 & 0.22 & 0.24 & 0.29 \\
\hline$\rho\left(R^{i}, \epsilon^{2}\right)$ & 0.19 & 0.19 & 0.18 & 0.17 & 0.17 & 0.16 & 0.16 & 0.16 & 0.15 & 0.14 & -0.16 \\
\hline$\rho\left(R^{i}, \epsilon^{3}\right)$ & -0.41 & -0.41 & -0.41 & -0.41 & -0.40 & -0.39 & -0.37 & -0.34 & -0.32 & -0.29 & 0.34 \\
\hline
\end{tabular}

Notes: Simulated return statistics for 10 portfolios formed according to price-dividend ratios.

Parameter values for the aggregate market are as in Table 4. The model is simulated at a quarterly frequency and returns are aggregated up to an annual frequency. Growth of the dividend shares is assumed to be constant at $20 \%$ p.a. for the first half of the life-cycle and at $-20 \%$ p.a. for the second half of the life-cycle. There is no lower bound for the dividend share. 
Table 10: Growth vs. Value Portfolios: Linear Growth with Lower Bound

\begin{tabular}{|c|c|c|c|c|c|c|c|c|c|c|c|}
\hline & $\mathrm{G}$ & & & & Growth & to Valu & & & & $\mathrm{V}$ & V-G \\
\hline Portfolio & 1 & 2 & 3 & 4 & 5 & 6 & 7 & 8 & 9 & 10 & $10-1$ \\
\hline$E R^{i}-R^{f}$ & 5.81 & 5.60 & 5.51 & 5.80 & 6.37 & 7.10 & 7.88 & 8.58 & 9.09 & 9.25 & 3.44 \\
\hline$\sigma\left(R^{i}-R^{f}\right)$ & 20.32 & 19.61 & 18.88 & 18.73 & 18.84 & 18.75 & 18.40 & 17.96 & 17.54 & 17.19 & 7.24 \\
\hline Sharpe Ratio & 0.29 & 0.29 & 0.29 & 0.31 & 0.34 & 0.38 & 0.43 & 0.48 & 0.52 & 0.54 & 0.48 \\
\hline \multicolumn{12}{|c|}{$\mathrm{CAPM}: R_{t}^{i}-R_{t}^{f}=\alpha_{i}+\beta_{i}\left(R_{t}^{m}-R_{t}^{f}\right)+\epsilon_{i t}$} \\
\hline$\alpha_{i}$ & -2.15 & -2.07 & -1.88 & -1.56 & -1.06 & -0.32 & 0.60 & 1.53 & 2.26 & 2.59 & 4.73 \\
\hline$\beta_{i}$ & 1.07 & 1.03 & 0.99 & 0.99 & 1.00 & 1.00 & 0.98 & 0.95 & 0.92 & 0.89 & -0.17 \\
\hline$R_{i}^{2}$ & 0.98 & 0.98 & 0.98 & 0.99 & 0.99 & 1.00 & 1.00 & 0.99 & 0.97 & 0.96 & 0.20 \\
\hline \multicolumn{12}{|c|}{ CAPM \& HML: $R_{t}^{i}-R_{t}^{f}=\alpha_{i}+\beta_{i}\left(R_{t}^{m}-R_{t}^{f}\right)+\gamma_{i} \mathrm{HML}_{t}+\epsilon_{i t}$} \\
\hline$\alpha_{i}$ & 0.02 & 0.00 & -0.04 & -0.04 & -0.02 & 0.00 & 0.00 & 0.01 & 0.02 & 0.02 & 0.00 \\
\hline$\beta_{i}$ & 0.99 & 0.95 & 0.93 & 0.93 & 0.96 & 0.98 & 1.00 & 1.00 & 1.00 & 0.99 & 0.00 \\
\hline$\gamma_{i}$ & -0.46 & -0.44 & -0.39 & -0.32 & -0.22 & -0.07 & 0.13 & 0.32 & 0.47 & 0.54 & 1.00 \\
\hline$R_{i}^{2}$ & 1.00 & 1.00 & 1.00 & 1.00 & 1.00 & 1.00 & 1.00 & 1.00 & 1.00 & 1.00 & 1.00 \\
\hline \multicolumn{12}{|c|}{ Unconditional Correlations } \\
\hline$\rho\left(R^{i}, M\right)$ & -0.07 & -0.07 & -0.07 & -0.07 & -0.08 & -0.09 & -0.10 & -0.11 & -0.12 & -0.13 & -0.12 \\
\hline$\rho\left(R^{i}, \epsilon^{1}\right)$ & 0.12 & 0.12 & 0.12 & 0.13 & 0.14 & 0.16 & 0.18 & 0.20 & 0.22 & 0.23 & 0.21 \\
\hline$\rho\left(R^{i}, \epsilon^{2}\right)$ & 0.17 & 0.18 & 0.19 & 0.19 & 0.18 & 0.17 & 0.16 & 0.16 & 0.15 & 0.15 & -0.13 \\
\hline$\rho\left(R^{i}, \epsilon^{3}\right)$ & -0.40 & -0.40 & -0.40 & -0.39 & -0.39 & -0.38 & -0.36 & -0.34 & -0.32 & -0.31 & 0.39 \\
\hline
\end{tabular}

Notes: Simulated return statistics for 10 portfolios formed according to price-dividend ratios.

Parameter values for the aggregate market are as in Table 4. The model is simulated at a quarterly frequency and returns are aggregated up to an annual frequency. Growth of the dividend shares is assumed to decline linearly from $75 \%$ p.a. to $-75 \%$ p.a. The lower bound for the dividend share is $0.1 \%$. 
Table 11: Growth vs. Value Portfolios: Constant Growth with Lower Bound

\begin{tabular}{|c|c|c|c|c|c|c|c|c|c|c|c|}
\hline & G & & & & Growth & to Valu & & & & $\mathrm{V}$ & $\mathrm{V}-\mathrm{G}$ \\
\hline Portfolio & 1 & 2 & 3 & 4 & 5 & 6 & 7 & 8 & 9 & 10 & $10-1$ \\
\hline$E R^{i}-R^{f}$ & 5.50 & 5.68 & 5.87 & 6.13 & 6.50 & 7.00 & 7.58 & 8.18 & 8.71 & 9.40 & 3.91 \\
\hline$\sigma\left(R^{i}-R^{f}\right)$ & 19.35 & 19.63 & 19.58 & 19.42 & 19.20 & 18.89 & 18.44 & 17.88 & 17.46 & 17.60 & 6.72 \\
\hline Sharpe Ratio & 0.28 & 0.29 & 0.30 & 0.32 & 0.34 & 0.37 & 0.41 & 0.46 & 0.50 & 0.53 & 0.58 \\
\hline \multicolumn{12}{|c|}{$\mathrm{CAPM}: R_{t}^{i}-R_{t}^{f}=\alpha_{i}+\beta_{i}\left(R_{t}^{m}-R_{t}^{f}\right)+\epsilon_{i t}$} \\
\hline$\alpha_{i}$ & -1.97 & -1.90 & -1.71 & -1.40 & -0.96 & -0.36 & 0.40 & 1.24 & 1.99 & 2.69 & 4.67 \\
\hline$\beta_{i}$ & 1.01 & 1.03 & 1.03 & 1.02 & 1.01 & 1.00 & 0.97 & 0.94 & 0.91 & 0.91 & -0.10 \\
\hline$R_{i}^{2}$ & 0.98 & 0.98 & 0.99 & 0.99 & 0.99 & 1.00 & 1.00 & 0.99 & 0.97 & 0.96 & 0.08 \\
\hline \multicolumn{12}{|c|}{ CAPM \& HML: $R_{t}^{i}-R_{t}^{f}=\alpha_{i}+\beta_{i}\left(R_{t}^{m}-R_{t}^{f}\right)+\gamma_{i} \mathrm{HML}_{t}+\epsilon_{i t}$} \\
\hline$\alpha_{i}$ & 0.02 & 0.02 & 0.02 & 0.02 & 0.02 & 0.02 & 0.02 & 0.02 & 0.03 & 0.02 & 0.00 \\
\hline$\beta_{i}$ & 0.97 & 0.99 & 0.99 & 0.99 & 0.99 & 0.99 & 0.98 & 0.97 & 0.95 & 0.97 & 0.00 \\
\hline$\gamma_{i}$ & -0.43 & -0.41 & -0.37 & -0.31 & -0.21 & -0.08 & 0.08 & 0.26 & 0.42 & 0.57 & 1.00 \\
\hline$R_{i}^{2}$ & 1.00 & 1.00 & 1.00 & 1.00 & 1.00 & 1.00 & 1.00 & 1.00 & 1.00 & 1.00 & 1.00 \\
\hline \multicolumn{12}{|c|}{ Unconditional Correlations } \\
\hline$\rho\left(R^{i}, M\right)$ & -0.09 & -0.09 & -0.09 & -0.10 & -0.11 & -0.12 & -0.13 & -0.14 & -0.16 & -0.17 & -0.19 \\
\hline$\rho\left(R^{i}, \epsilon^{1}\right)$ & 0.15 & 0.15 & 0.15 & 0.16 & 0.17 & 0.18 & 0.20 & 0.22 & 0.24 & 0.26 & 0.27 \\
\hline$\rho\left(R^{i}, \epsilon^{2}\right)$ & 0.19 & 0.18 & 0.18 & 0.18 & 0.17 & 0.17 & 0.16 & 0.16 & 0.15 & 0.14 & -0.16 \\
\hline$\rho\left(R^{i}, \epsilon^{3}\right)$ & -0.39 & -0.39 & -0.38 & -0.38 & -0.37 & -0.37 & -0.35 & -0.33 & -0.31 & -0.29 & 0.35 \\
\hline
\end{tabular}

Notes: Simulated return statistics for 10 portfolios formed according to price-dividend ratios.

Parameter values for the aggregate market are as in Table 4 . The model is simulated at a quarterly frequency and returns are aggregated up to an annual frequency. Growth of the dividend shares is assumed to be constant at $20 \%$ p.a. for the first half of the life-cycle and at $-20 \%$ p.a. for the second half of the life-cycle. The lower bound for the dividend share is $0.1 \%$. 
Figure 1: Model Solution
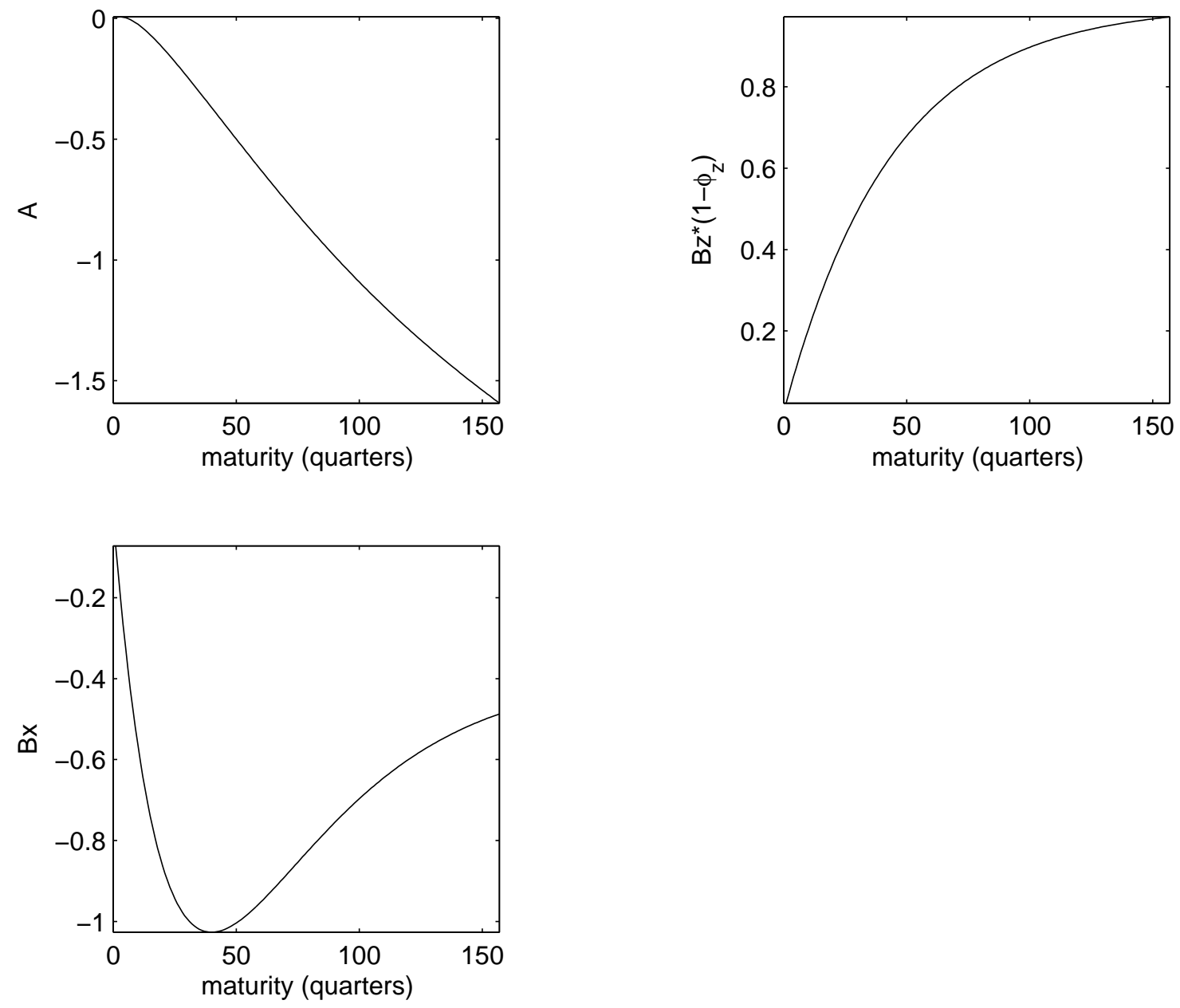

Notes: This figure shows the solutions of the system of algebraic equations (11)(13) for the parameter values in Table 4. 
Figure 2: Price/Dividend Ratio of Zero-Coupon Equity
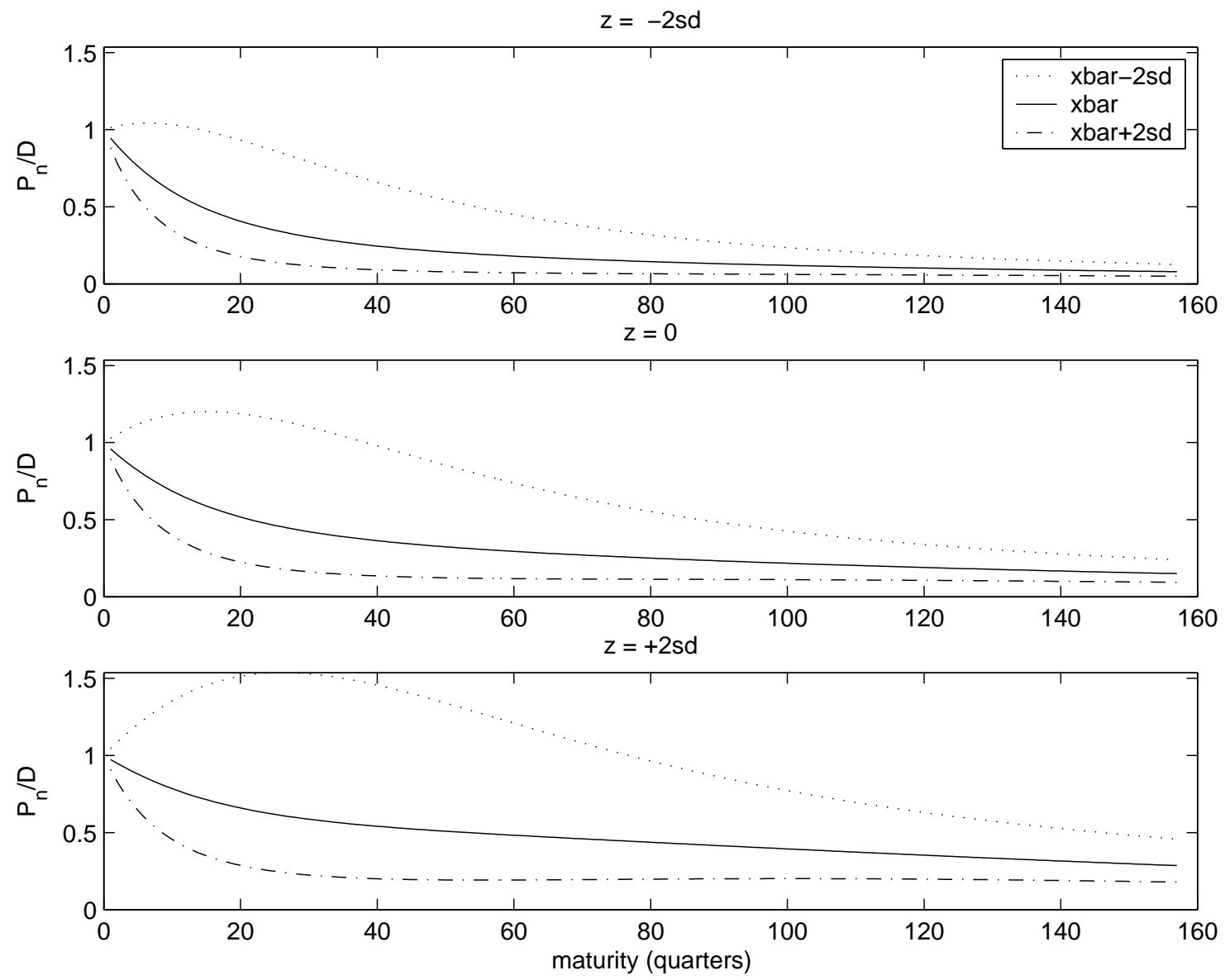

Notes: This figure plots the ratio of the price of $n$-period zero-coupon equity to the aggregate (quarterly) dividend as a function of maturity $n$ for the parameter values in Table 4 . The three panels show the zero-coupon curves for $z=-2\left\|\sigma_{z}\right\| / \sqrt{1-\phi_{z}^{2}}, z=0$ and $z=2\left\|\sigma_{z}\right\| / \sqrt{1-\phi_{z}^{2}}$. Each panel plots three graphs for $x=\bar{x}-2\left\|\sigma_{x}\right\| / \sqrt{1-\phi_{x}^{2}}, x=\bar{x}$ and $x=\bar{x}+2\left\|\sigma_{x}\right\| / \sqrt{1-\phi_{x}^{2}}$. 
Figure 3: Properties of Zero-Coupon Equity
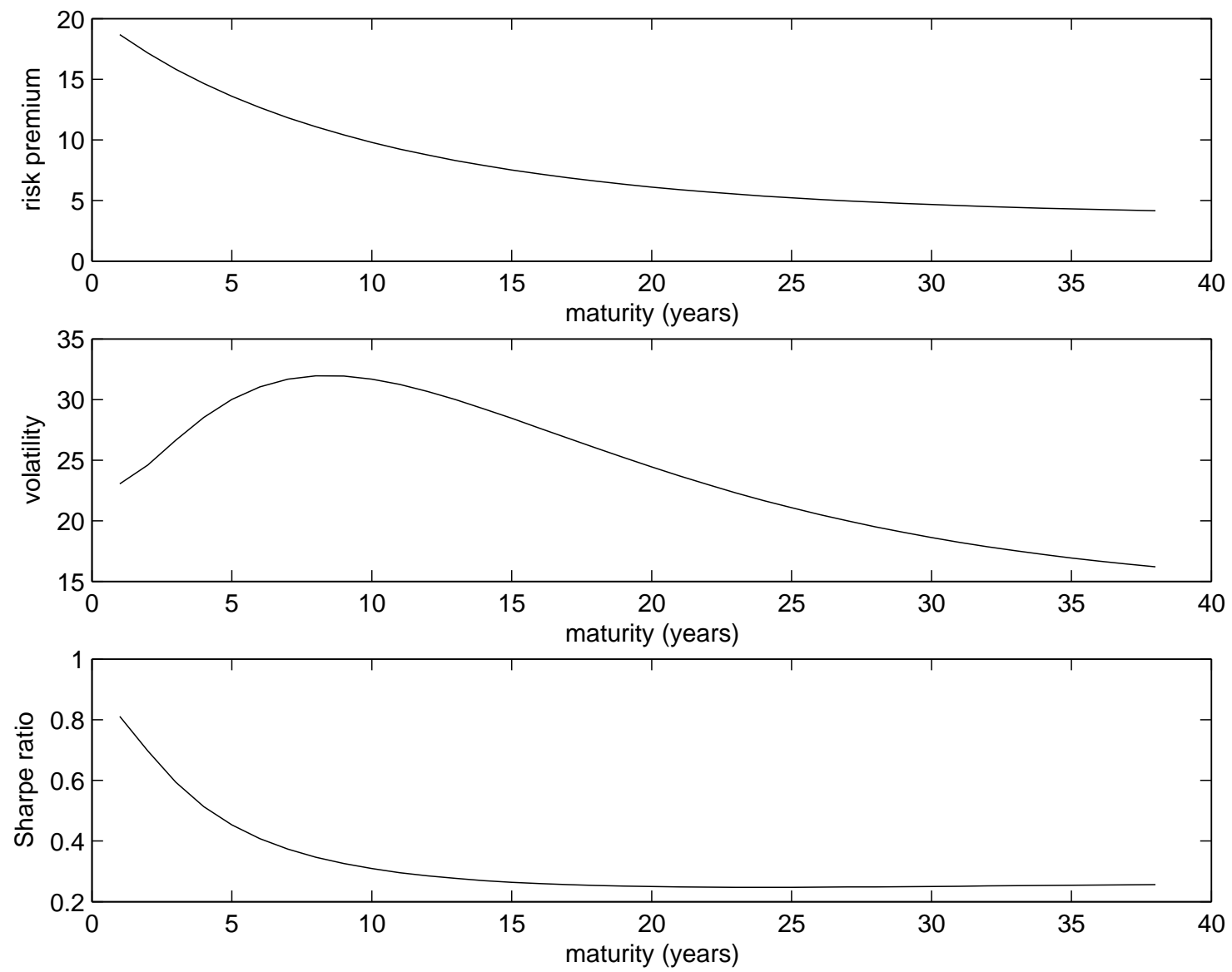

Notes: This figure shows return statistics for zero-coupon equity as a function of maturity. The top panel plots risk premia of annual level returns over the riskfree rate. The second panel plots the standard deviation of annual level returns. The third panel plot the Sharpe ratio (risk premia dividend by standard deviation). 
Figure 4: CAPM Regressions for Zero-Coupon Equity
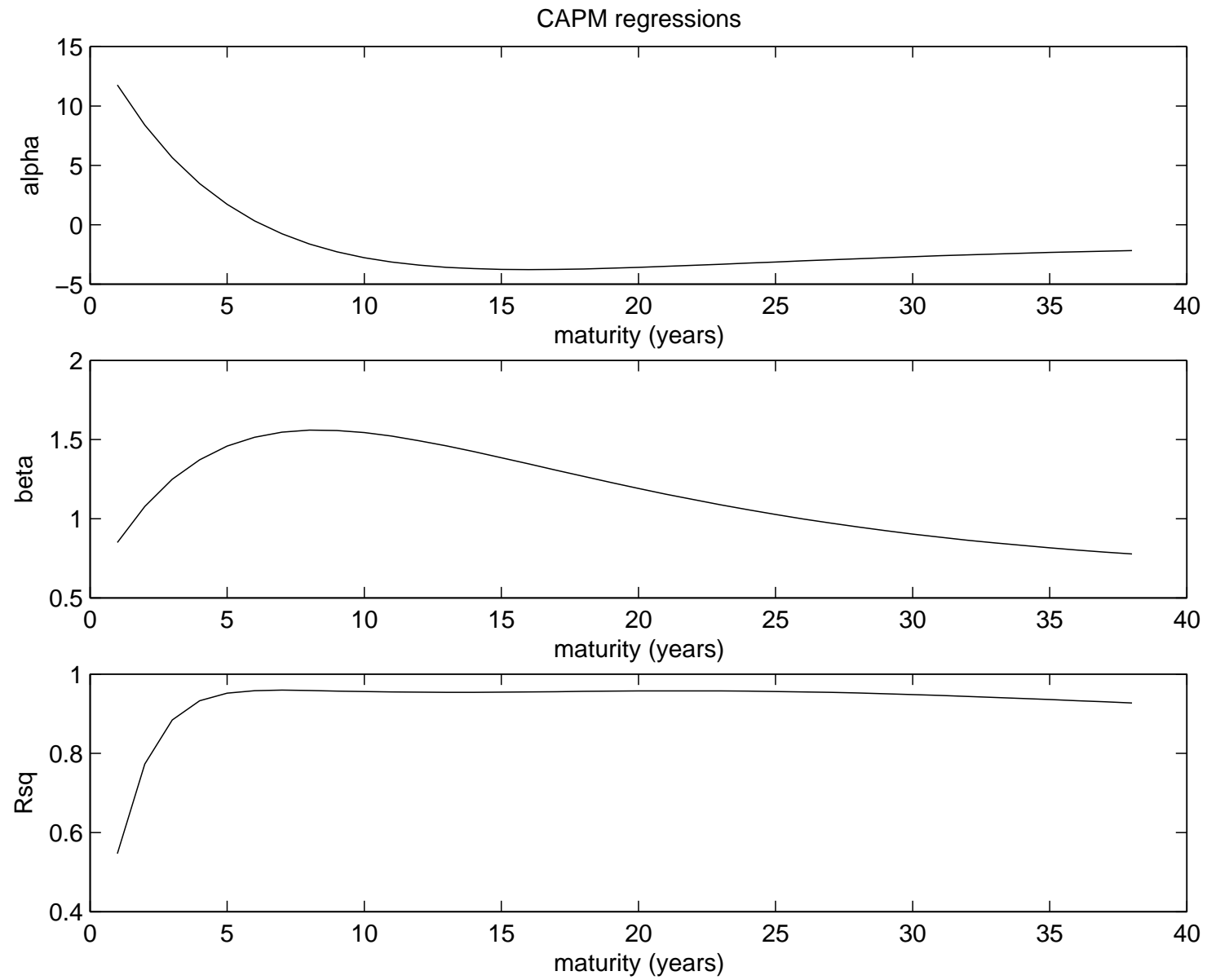

Notes: This figure shows results from unconditional CAPM regressions of annual returns of zero-coupon equity on the market return. The top panel plots $\alpha^{(n)}$, the middle panel plots $\beta^{(n)}$ and the bottom panel plots the $R^{2(n)}$ as a function of maturity. 
Figure 5: Cross-Sectional Distribution - Linear Growth

The CDF of the Cross-Section of Growth Rates

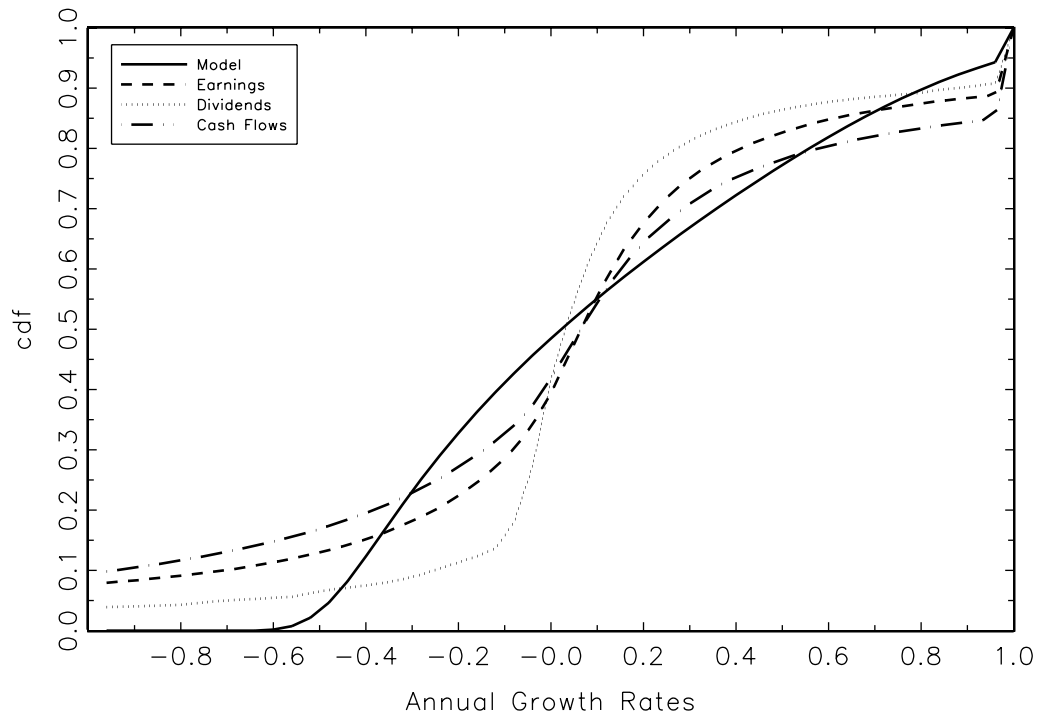

The CDF of the Cross-Section of Price Ratios

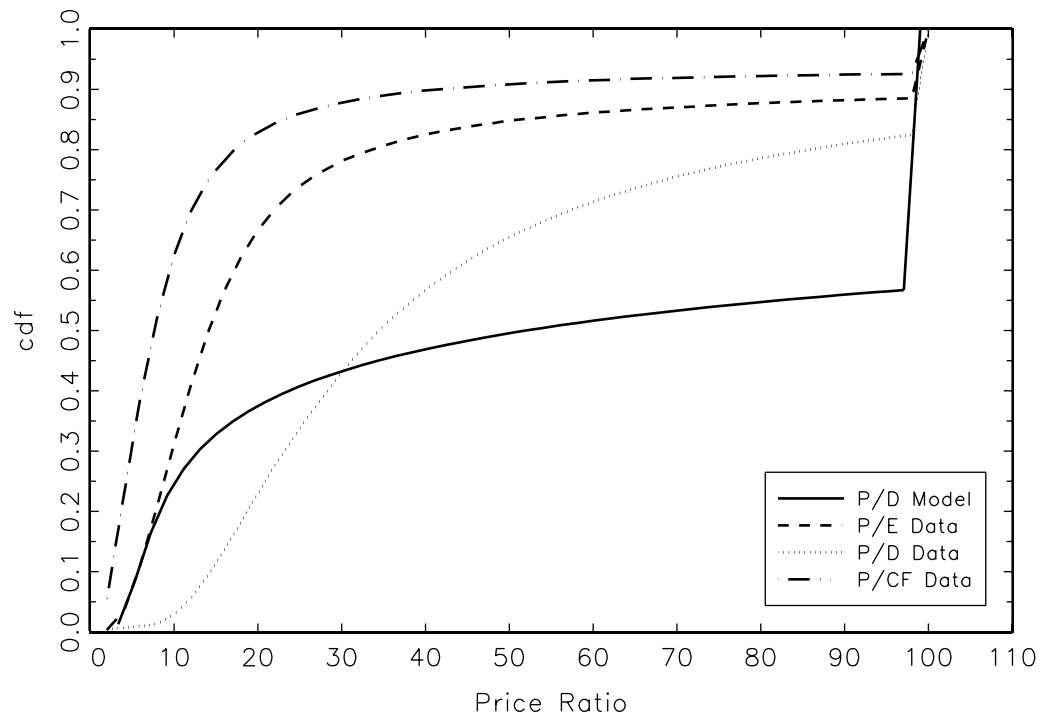

Notes: This figure compares the cross-sectional distribution of growth rates of various cash flow measures and price ratios in the model (assuming linearly declining growth in shares) to those in the data. The top panel plots the distribution of annual growth rates of dividends, earnings and cash flows across all firms for the 1952 - 2002 period. Growth rates are censored at 100\%. Firms that exit the sample are assigned a growth rate of $-100 \%$. The solid line is the distribution of annual dividend growth rates for all firms in a simulation of 50,000 quarters. The bottom panel plots the corresponding distribution of various price multiples in the data and in the simulated model. 
Figure 6: Cross-Sectional Distributions - Constant Growth

The CDF of the Cross-Section of Growth Rates

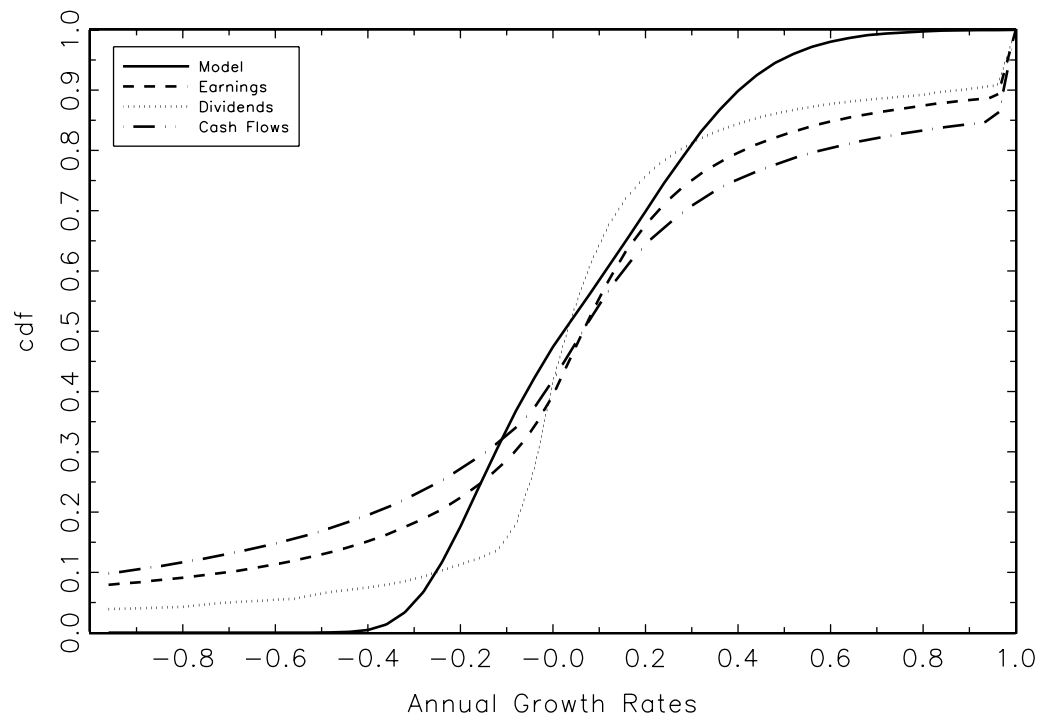

The CDF of the Cross-Section of Price Ratios

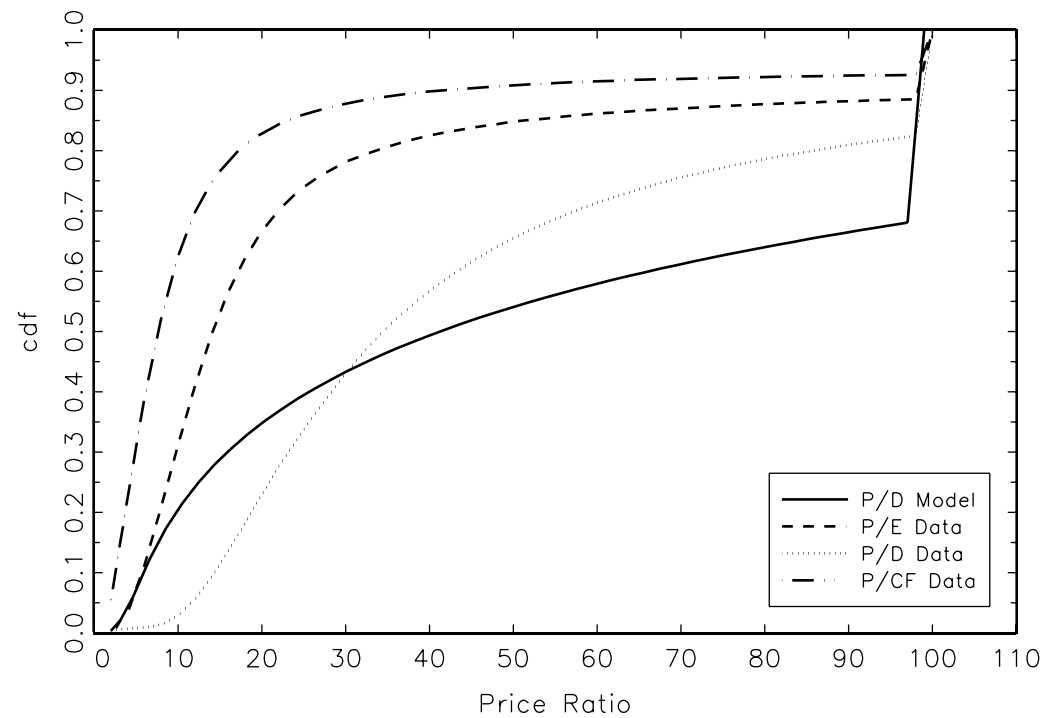

Notes: This figure compares the cross-sectional distribution of growth rates of various cash flow measures and price ratios in the model (assuming constant growth in shares) to those in the data. The top panel plots the distribution of annual growth rates of dividends, earnings and cash flows across all firms for the 1952 - 2002 period. Growth rates are censored at 100\%. Firms that exit the sample are assigned a growth rate of $-100 \%$. The solid line is the distribution of annual dividend growth rates for all firms in a simulation of 50,000 quarters. The bottom panel plots the corresponding distribution of various price multiples in the data and in the simulated model. 
Figure 7: Effect of $\rho_{d x}$ on Zero-Coupon Equity
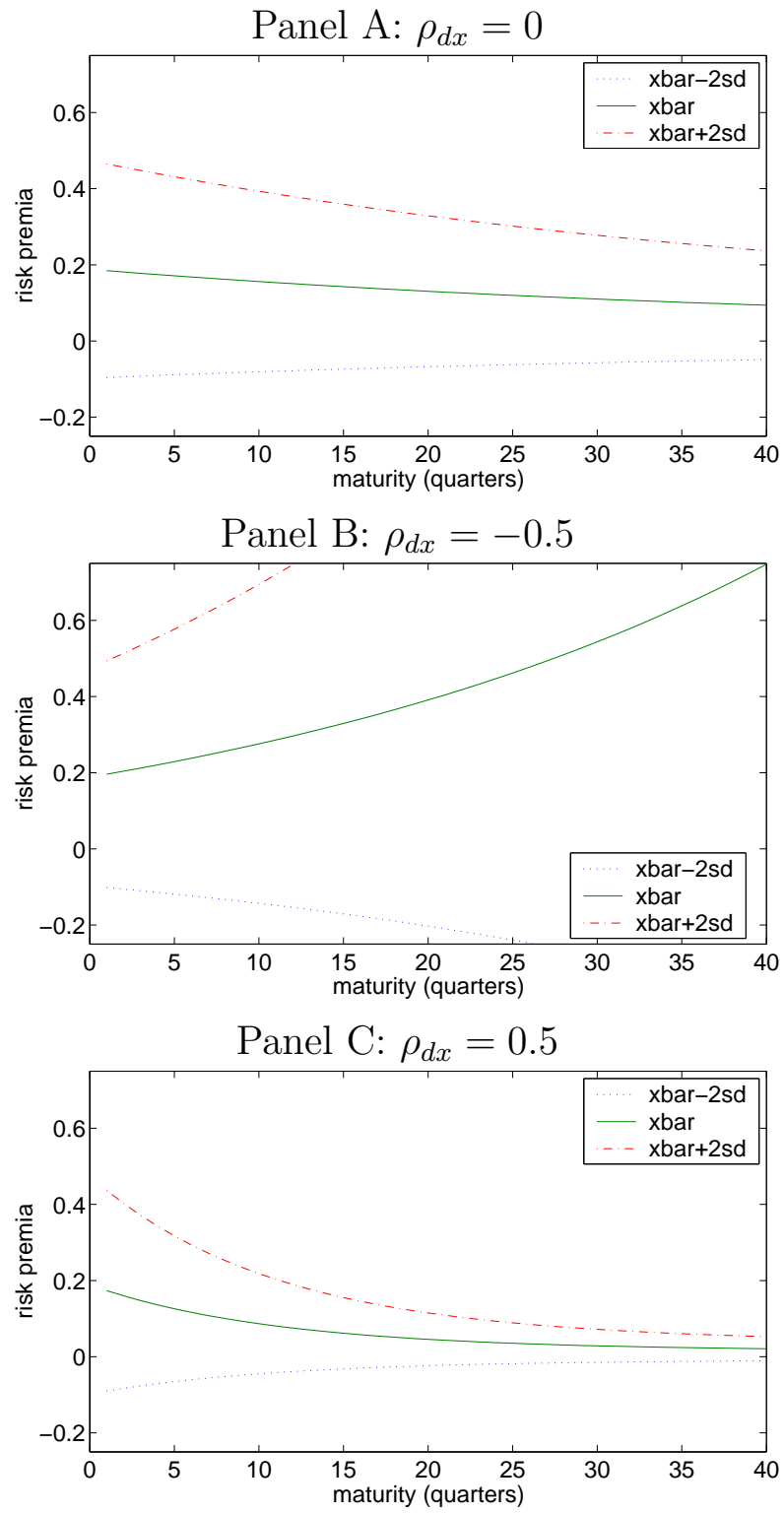

Notes: The three panels show risk premia for zero-coupon equity as a function of the maturity for the parameter values in Table 4. Each panel has three graphs that plot risk premia at the mean of $x_{t}, \bar{x}$, and plus and minus two long-run standard deviations from $\bar{x}$. The top panel assumes that the correlation of dividend shocks and shocks to $x_{t}$ is zero, the middle panel assumes that the correlation of dividend shocks and shocks to $x_{t}$ is -0.5 and the bottom panel assumes that the correlation of dividend shocks and shocks to $x_{t}$ is 0.5 . All other parameter values are identical. 
Figure 8: Regressions on Fundamental Shocks
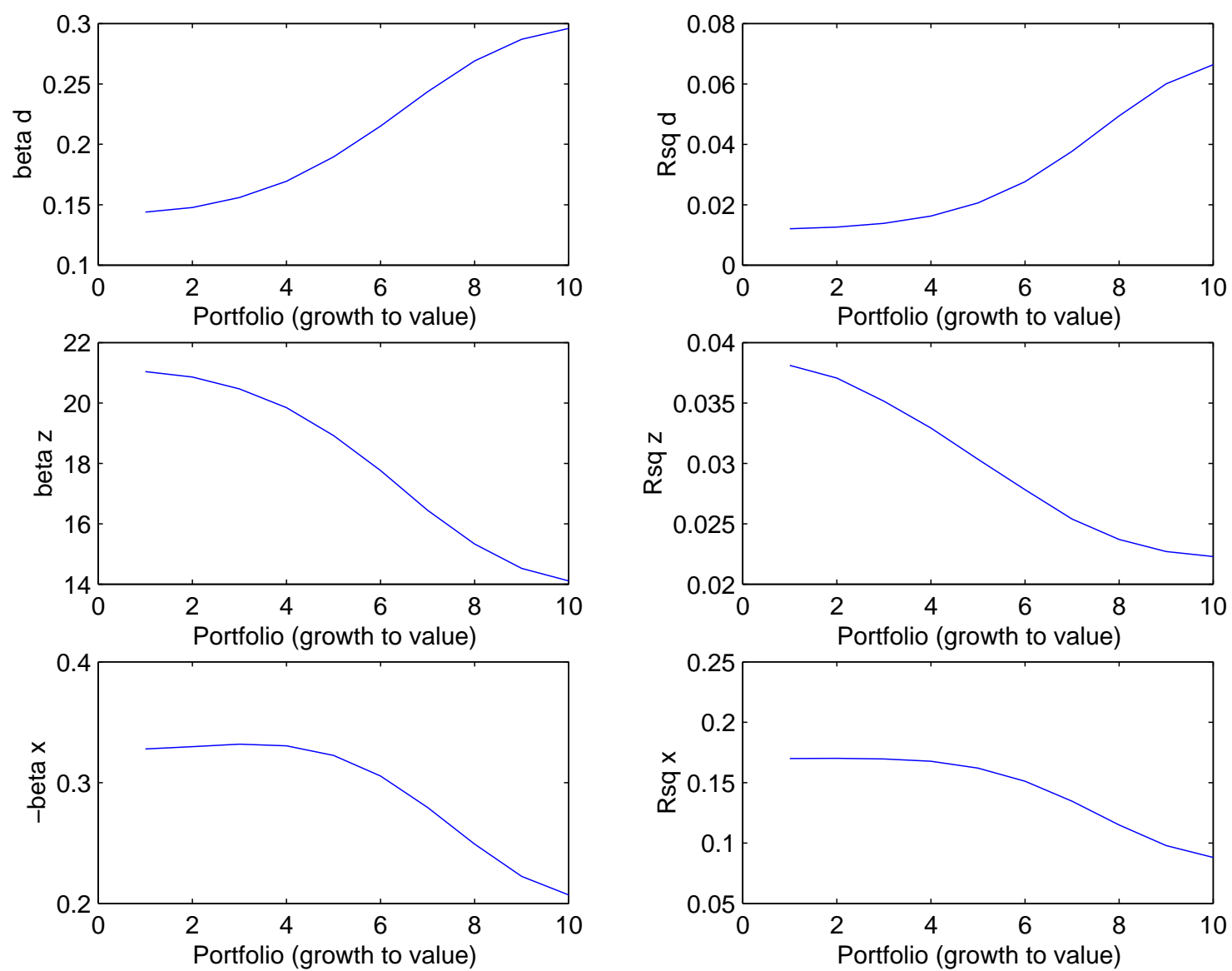

Notes: This figure plots the OLS coefficients and $R^{2}$ statistics from regressions of annual portfolio returns on the fundamental shocks. Firms are constructed assuming linearly decreasing dividend growth. The top panels regress portfolio returns on the shock to dividends $2 \sigma_{d} \epsilon_{t}$, the middle panels regress portfolio returns on the shocks to the component of expected dividend growth that is uncorrelated with the shock to dividends $2 \sigma_{z}(2) \epsilon_{t}(2)$, and the bottom panels regress firm returns on the shocks to the Sharpe ratio $2 \sigma_{x} \epsilon_{t}$ (note that the shocks to the Sharpe ratio are uncorrelated with shocks to dividends and expected dividends). 
Figure 9: Cross-Sectional Distributions - Linear Growth with with Lower Bound

The CDF of the Cross-Section of Growth Rates

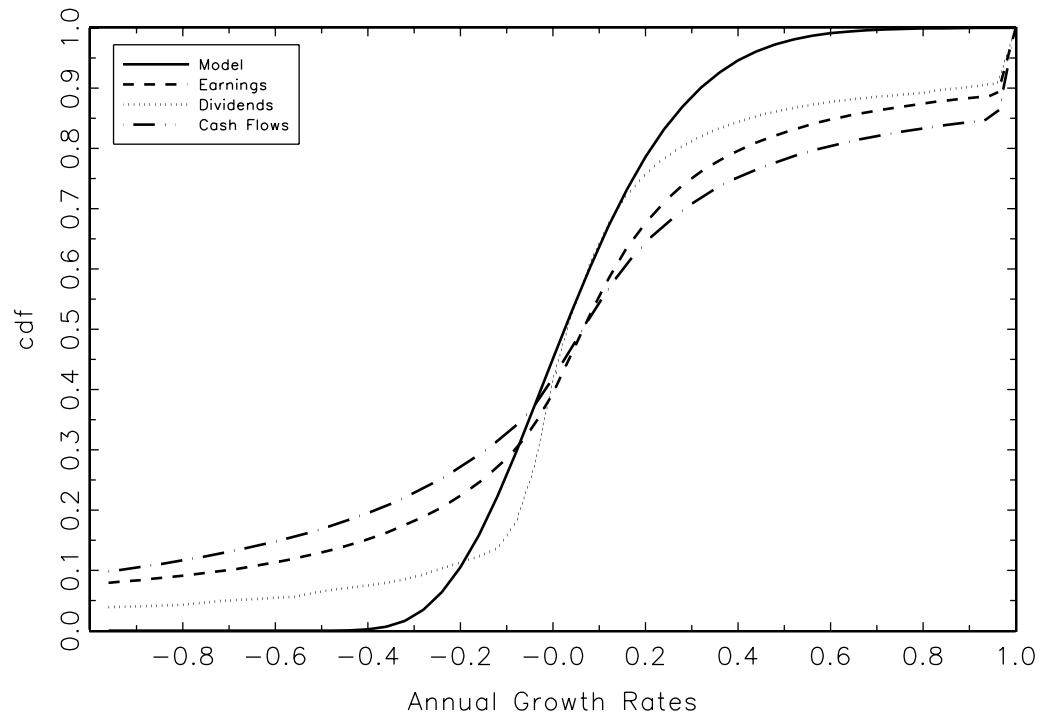

The CDF of the Cross-Section of Price Ratios

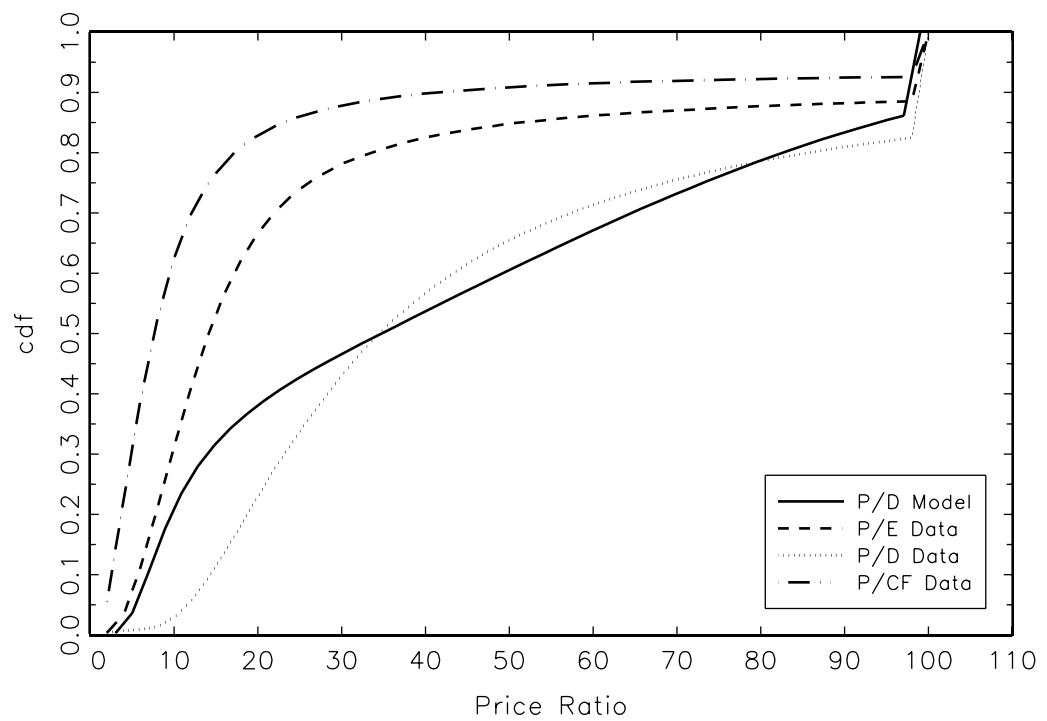

Notes: This figure compares the cross-sectional distribution of growth rates of various cash flow measures and price ratios in the model (assuming linearly declining growth in shares with a lower bound of $0.1 \%$ ) to those in the data. The top panel plots the distribution of annual growth rates of dividends, earnings and cash flows across all firms for the 1952 - 2002 period. Growth rates are censored at $100 \%$. Firms that exit the sample are assigned a growth rate of $-100 \%$. The solid line is the distribution of annual dividend growth rates for all firms in a simulation of 50,000 quarters. The bottom panel plots the corresponding distribution of various price multiples in the data and in the simulated model. 
Figure 10: Cross-Sectional Distributions - Constant Growth with Lower Bound

The CDF of the Cross-Section of Growth Rates

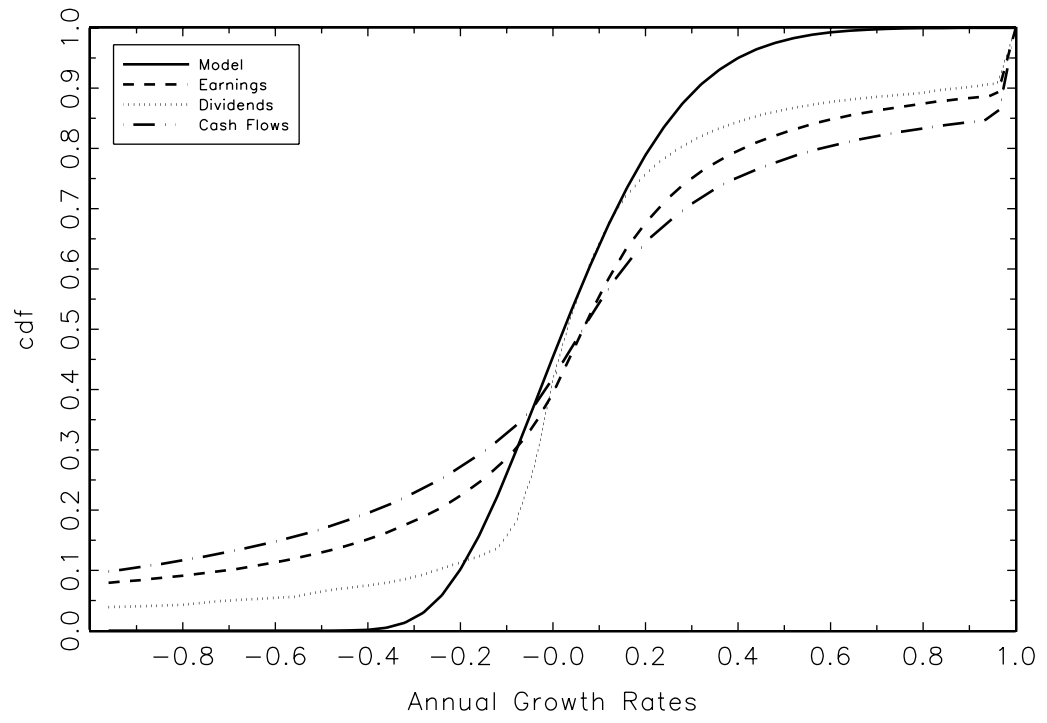

The CDF of the Cross-Section of Price Ratios

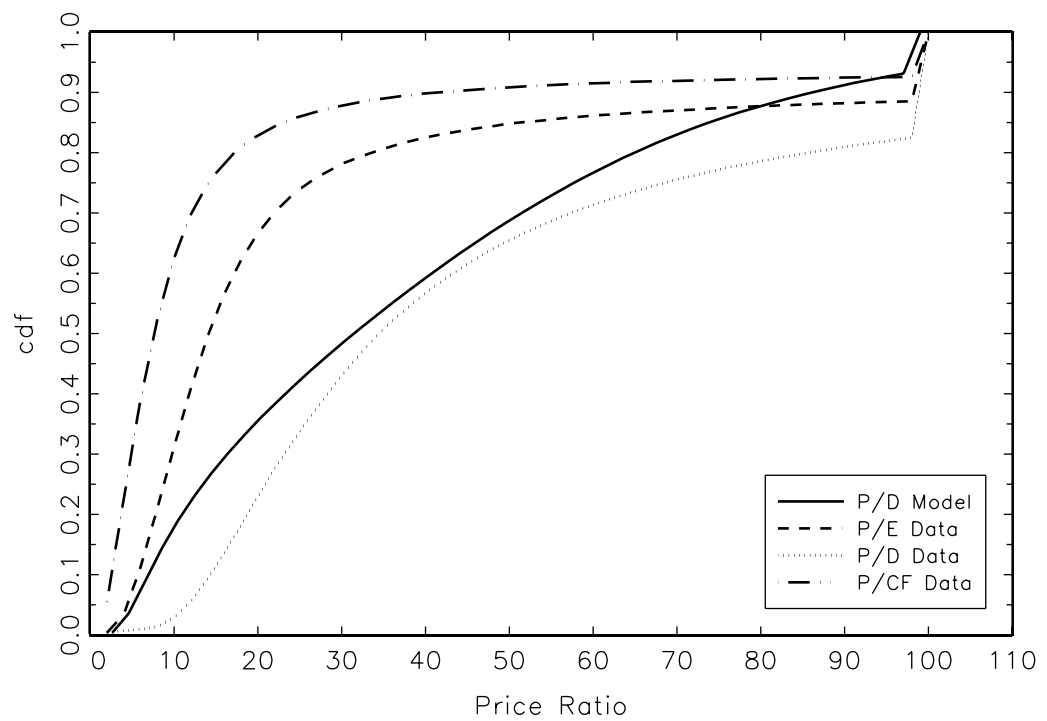

Notes: This figure compares the cross-sectional distribution of growth rates of various cash flow measures and price ratios in the model (assuming constant growth in shares with a lower bound of $0.1 \%$ ) to those in the data. The top panel plots the distribution of annual growth rates of dividends, earnings and cash flows across all firms for the 1952 - 2002 period. Growth rates are censored at $100 \%$. Firms that exit the sample are assigned a growth rate of $-100 \%$. The solid line is the distribution of annual dividend growth rates for all firms in a simulation of 50,000 quarters. The bottom panel plots the corresponding distribution of various price multiples in the data and in the simulated model. 